\title{
Global Warming Pattern Formation: Sea Surface Temperature and Rainfall*
}

\author{
Shang-Ping Xie, ${ }^{+}$Clara Deser,,${ }^{\#}$ Gabriel A. Vecchi, ${ }^{@}$ Jian Ma, ${ }^{+}$Haiyan Teng, ${ }^{\#}$ \\ AND ANDREw T. WitTENBERG ${ }^{\circledR}$ \\ ${ }^{+}$International Pacific Research Center, and Department of Meteorology, SOEST, University of Hawaii \\ at Manoa, Honolulu, Hawaii \\ \# Climate and Global Dynamics Division, National Center for Atmospheric Research, Boulder, Colorado \\ @NOAA/Geophysical Fluid Dynamics Laboratory, Princeton, New Jersey
}

(Manuscript received 1 July 2009, in final form 14 September 2009)

\begin{abstract}
Spatial variations in sea surface temperature (SST) and rainfall changes over the tropics are investigated based on ensemble simulations for the first half of the twenty-first century under the greenhouse gas (GHG) emission scenario A1B with coupled ocean-atmosphere general circulation models of the Geophysical Fluid Dynamics Laboratory (GFDL) and National Center for Atmospheric Research (NCAR). Despite a GHG increase that is nearly uniform in space, pronounced patterns emerge in both SST and precipitation. Regional differences in SST warming can be as large as the tropical-mean warming. Specifically, the tropical Pacific warming features a conspicuous maximum along the equator and a minimum in the southeast subtropics. The former is associated with westerly wind anomalies whereas the latter is linked to intensified southeast trade winds, suggestive of wind-evaporation-SST feedback. There is a tendency for a greater warming in the northern subtropics than in the southern subtropics in accordance with asymmetries in trade wind changes. Over the equatorial Indian Ocean, surface wind anomalies are easterly, the thermocline shoals, and the warming is reduced in the east, indicative of Bjerknes feedback. In the midlatitudes, ocean circulation changes generate narrow banded structures in SST warming. The warming is negatively correlated with wind speed change over the tropics and positively correlated with ocean heat transport change in the northern extratropics. A diagnostic method based on the ocean mixed layer heat budget is developed to investigate mechanisms for SST pattern formation.

Tropical precipitation changes are positively correlated with spatial deviations of SST warming from the tropical mean. In particular, the equatorial maximum in SST warming over the Pacific anchors a band of pronounced rainfall increase. The gross moist instability follows closely relative SST change as equatorial wave adjustments flatten upper-tropospheric warming. The comparison with atmospheric simulations in response to a spatially uniform SST warming illustrates the importance of SST patterns for rainfall change, an effect overlooked in current discussion of precipitation response to global warming. Implications for the global and regional response of tropical cyclones are discussed.
\end{abstract}

\section{Introduction}

The atmospheric concentration of carbon dioxide $\left(\mathrm{CO}_{2}\right)$ has been steadily increasing since the Industrial Revolution and will continue to increase for the foreseeable future. The increasing concentrations of $\mathrm{CO}_{2}$ and other

\footnotetext{
* International Pacific Research Center/School of Ocean and Earth Science and Technology Publication Number 633/7811.

Corresponding author address: Shang-Ping Xie, International Pacific Research Center, SOEST, University of Hawaii at Manoa, Honolulu, HI 96822.

E-mail: xie@hawaii.edu
}

greenhouse gases (GHGs) in the atmosphere are considered as the major cause of global-mean surface air temperature (SAT) rise observed during the twentieth century and are projected to accelerate the rate of global warming (Meehl et al. 2007). Various climate feedbacks such as the one involving water vapor are important for the warming magnitude and its uncertainties (Soden and Held 2006; Bony et al. 2006). Much attention has been directed to study these climate feedbacks and relevant physical processes (e.g., cloud microphysics). Global warming, however, involves much more than just a warming of global-mean SAT. There are well-known patterns of SAT warming in response to GHG increases, at least in models: for example, surface warming is much stronger 
over land because of less efficient evaporative cooling and smaller heat capacity than over ocean (Sutton et al. 2007); it displays a tendency of polar amplification especially in the Northern Hemisphere because of ice/snow albedo feedback (Manabe et al. 1990) and increased polarward energy transport by atmospheric eddies (Cai 2005); and the warming is weak over the deep- (bottom-) water formation region over the subpolar North Atlantic (Southern Ocean) because of the deep winter mixed layer and circulation changes (Manabe et al. 1990). The increased poleward gradients of sea surface temperature affect storm tracks in the North Atlantic and Southern Hemisphere (Yin 2005; Inatsu and Kimoto 2005).

Tropical patterns of global warming are not as well known nor as systematically studied as has been the global mean. This is because spatial variations in surface warming within the tropics are considerably smaller than the warming contrast between land and sea and between the Arctic and lower latitudes, making them hard to discern on a global map of SAT change. Small changes in tropical SST nevertheless can be highly influential on climate, as illustrated by observed climate variability. For example, over the tropical Atlantic and Indian Oceans, SST anomalies on the order of only $0.5^{\circ} \mathrm{C}$ induce atmospheric anomalies not only locally but over remote areas (see recent reviews by Chang et al. 2006; Schott et al. 2009). Of larger magnitude and more expansive in space, SST anomalies over the large Pacific basin associated with El Niño-Southern Oscillation (ENSO) have long-lasting climatic effects over the entire globe (e.g., Alexander et al. 2002).

In model projections, precipitation change is often characterized as a so-called wet-get-wetter pattern, increasing in the core of major tropical rainbands and decreasing on their edges and in dry subtropical regions. This wet-get-wetter pattern is generally explained in terms of increased moisture gradients in both the horizontal and vertical and resultant dry advection away from the core rainbands (Chou and Neelin 2004; Held and Soden 2006; Chou et al. 2009). Tropical Pacific SST warming displays patterns such as what Liu et al. (2005) call the equatorial-enhanced response (EER) (Knutson and Manabe 1995; Meehl et al. 2000). A question arises. While tropical anomalies of precipitation and SST are commonly known to interact strongly as in ENSO, it is unclear whether and how GHG-induced tropical precipitation change is related to SST patterns.

The present study is a general survey of tropical patterns and their formation under global warming. We wish to address the following fundamental questions. Although $\mathrm{CO}_{2}$ concentration in the atmosphere is nearly uniform in the horizontal, do patterns emerge in response to GHG increase? What do these patterns look like, and why do they form? Do they look like modes of natural variability? What are the atmospheric effects of these SST patterns? With instrumental records still too short and too sparse to detect reliably spatial patterns of global warming amid natural variability, we have to rely on model simulations at this point. Recognizing that model errors are inevitable, we believe that identifying pattern formation mechanisms and studying their physics are the way to make solid progress. Such a physical understanding is likely to hold and be useful in interpreting patterns that eventually emerge in the future from sustained observations, even though the relative importance of various mechanisms might turn out to be different.

The formation of current climate may be relevant to the problem of global warming pattern formation. Despite an annual-mean solar radiation distribution that is zonally uniform and symmetric about the equator, strong zonal and meridional asymmetries emerge, as illustrated by the equatorial cold tongue and northward displaced intertropical convergence zone in the Pacific and Atlantic. The Bjerknes (1969) and wind-evaporationSST (WES) (Xie and Philander 1994) feedbacks are important for the development of zonal and meridional asymmetry over equatorial oceans, respectively. A natural question is whether similar ocean-atmosphere interactions are important for global warming pattern formation.

The present study identifies major patterns of changes in SST, precipitation, surface wind, and ocean circulation in global warming simulations and investigates their formation mechanisms. Our investigation is based on ensemble simulations for the next half century carried out at the Geophysical Fluid Dynamics Laboratory (GFDL) and National Center for Atmospheric Research (NCAR). Substantial spatial variations in SST change emerge, typically about $25 \%$ of the tropical mean in standard deviation of spatial variations. Ocean-atmosphere interactions are, indeed, important for SST pattern formation but may operate in ways different than we are familiar with in current climate. We show that SST patterns exert strong controls on spatial variations in precipitation changes. Along with the recent studies of tropical cyclone (TC) response to climate changes (e.g., Vecchi and Soden 2007a; Knutson et al. 2008; Swanson 2008; Vecchi et al. 2008; Zhao et al. 2009), our study puts the spotlight on spatial patterns of tropical SST warming and their role in tropical and global climate change. Our approach is to highlight important processes for pattern formationleaving in-depth, quantitative analyses for future studies.

The rest of the paper is organized as follows. Section 2 describes the model simulations. Section 3 develops a diagnostic method for studying SST patterns. Major 
results based on the GFDL model simulation are presented in sections 4 and 5, which discuss SST patterns and explore their formation mechanisms. Section 6 presents results from the NCAR model simulation and compares with the GFDL one. Section 7 investigates the relationship between SST and precipitation patterns. Section 8 discusses implications for tropical cyclone change. Section 9 is a summary. Sections 4-8 present a number of oceanatmospheric patterns. Readers may skip to (sub)sections of interest.

\section{Models}

We analyze global warming simulations by two major U.S. climate models: the NOAA GFDL Climate Model, version 2.1 (CM2.1), and the NCAR Community Climate System Model, version 3 (CCSM3). Long integrations ( $\sim 1000$ years) have been performed under current climate forcing without flux correction, reaching statistically steady states similar to observations.

The CM2.1 uses the Flexible Modeling System (FMS) to couple the GFDL Atmospheric Model version 2.1 (AM2.1) with the Modular Ocean Model version 4 (MOM4). The AM2.1 builds on a finite volume atmospheric dynamical core and includes atmospheric physical packages and a land surface model. Its resolution is $2^{\circ}$ latitude $\times 2.5^{\circ}$ longitude with 24 vertical levels, 9 of which are located in the lowest $1.5 \mathrm{~km}$ to represent the planetary boundary layer. The ocean model uses a finite difference approach to solve the primitive equations. The resolution is $1^{\circ}$ longitude $\times 1^{\circ}$ latitude with meridional grid spacing decreasing to $1 / 3^{\circ}$ toward the equator. The model has 50 vertical levels, 22 of which are in the upper $220 \mathrm{~m}$. A detailed description of CM2.1 can be found in Anderson et al. (2004) and Delworth et al. (2006). The model simulates the current tropical climate quite realistically, including the annual-mean state, seasonal cycle, and major modes of interannual variability (Wittenberg et al. 2006).

The CCSM3 is a coupled model of ocean, atmosphere, land, and sea ice. The Community Atmosphere Model version 3 (CAM3) uses an Eulerian spectral dynamical core and includes physical packages for convection, turbulence, and cloud. The model uses triangular truncation at T42 (equivalent grid spacing of $2.8^{\circ}$ ) and has 26 vertical levels. Based on the Parallel Ocean Program (POP) version 1.4.3 from the Los Alamos National Laboratory, the ocean component has a horizontal resolution of $1^{\circ}$ and 40 vertical levels. Further details on CCSM3 may be found in Collins et al. (2006). Deser et al. (2006) present its simulation in the tropics.

The Intergovernmental Panel on Climate Change (IPCC) Special Report on Emissions Scenarios (SRES)
A1B scenario for the emission of a few climatically important trace gases (e.g., carbon dioxide and ozone) is based on certain socioeconomic development paths for the twenty-first century. It projects a rough doubling of atmospheric $\mathrm{CO}_{2}$ for the century as well as recovery of the Southern Hemisphere "ozone hole" by approximately 2050. A 10-member ensemble simulation has been completed at GFDL for the A1B scenario up to 2050. At NCAR, a 30-member ensemble simulation has been carried out up to 2062. In this paper, we analyze ensemble-mean, 50-yr difference fields for these A1B simulations: 2046-50 minus 1996-2000 for CM2.1 and 2051-60 minus 2001-10 for CCSM3. The use of ensemble means helps reduce natural variability and isolate the response to GHG increase. Changes in climate forcing between these two $50-\mathrm{yr}$ periods are slightly different but similar enough for our purposes. In A1B, the atmospheric $\mathrm{CO}_{2}$ concentration rises by $163 \mathrm{ppm}$ from $369 \mathrm{ppm}$ in 2000 to $532 \mathrm{ppm}$ in 2050. CM2.1 features a higher climate sensitivity than CCSM3, with a slightly stronger warming over $50 \mathrm{yr}$. The annual-mean SST rise averaged in the tropics $\left(30^{\circ} \mathrm{S}-30^{\circ} \mathrm{N}\right)$ is $1.05^{\circ} \mathrm{C}$ in $\mathrm{CM} 2.1$ and $1.01^{\circ} \mathrm{C}$ in CCSM3. CM2.1 features larger spatial variations in SST change than CCSM3 $\left(0.27^{\circ} \mathrm{C}\right.$ versus $0.22^{\circ} \mathrm{C}$ in standard deviation). Our presentation of results will be centered on CM2.1, but comparison will be made with CCSM3.

\section{SST pattern formation: Physical background}

Integrating the ocean temperature equation from the surface to the bottom of the mixed layer yields the SST equation

$$
C \frac{\partial T^{\prime}}{\partial t}=D_{o}+Q_{\text {net }},
$$

where $T^{\prime}$ is SST change, $C=c_{p}^{o} \rho_{o} H$ is the heat capacity of the mixed layer, $c_{p}^{o}$ and $\rho_{o}$ are the specific heat at constant pressure and density of seawater, $H$ is the mixed layer depth, $Q_{\text {net }}$ is the change for $50 \mathrm{yr}$ in the net surface heat flux into the ocean (positive downward), and $D_{o}$ is the ocean heat transport effect due to threedimensional advection and mixing (including entrainment at the base of the mixed layer). For the global mean, the SST response to an abrupt $\mathrm{CO}_{2}$ doubling displays at least two distinct time scales: the fast response of the mixed layer warming and a slow response to warm the thermocline and deeper water masses via mixing and ventilation (Dickinson 1981; Manabe et al. 1990). The former takes a few years [as can be inferred from the slab ocean mixed layer (OML) model experiments], and the latter tens to hundreds years or longer (Stouffer 2004). 
The present study concerns SST pattern formation for the first half of the twenty-first century. For a slowly increasing GHG scenario like A1B, SST warming at this early stage is dominated by mixed layer and upperocean processes that are in a quasi equilibrium with the slow GHG forcing. Indeed, tropical-mean SST $\left(30^{\circ} \mathrm{S}-\right.$ $30^{\circ} \mathrm{N}$ ) increases by $1^{\circ} \mathrm{C}$ for $50 \mathrm{yr}$ in $\mathrm{CM}$ and CCSM, equivalent to a rate of heat content change of $0.25 \mathrm{~W} \mathrm{~m}^{-2}$ for a 100-m-deep mixed layer [left hand side of Eq. (1)]. By comparison, spatial variations in $Q_{\text {net }}$ are one order of magnitude larger, amounting to $3.4 \mathrm{~W} \mathrm{~m}^{-2}$ in standard deviation over the tropics. Thus, for our discussion of spatial pattern formation, the ocean transport effect balances the net surface flux to first order,

$$
D_{o}=-Q_{\text {net }} .
$$

This is a convenient diagnostic relationship that we use in this paper to infer the ocean heat transport effect without explicitly calculating all of the advection and mixing terms. Often $D_{o}$ is dominated by advection of mean SST gradients by anomalous currents. In such cases, we can cross-validate this relationship against changes in surface current. Equation (2) misses pattern formation mechanisms due to slow ocean processes such as the deep water ventilation, but they do not seem dominant in the tropics for the first 50 years of A1B simulations.

Surface heat flux consists of four physical components: solar radiation $Q_{S}$, longwave radiation $Q_{L}$, and turbulent fluxes of sensible heat $Q_{H}$ and latent heat $Q_{E}$. In models, latent heat flux is calculated using a bulk formula,

$$
\begin{aligned}
Q_{E} & =L \rho_{a} C_{E} W\left[q_{s}(T)-q_{a}\right] \\
& =L \rho_{a} C_{E} W\left[q_{s}(T)-\mathrm{RH} q_{s}(T+S)\right] \\
& =L \rho_{a} C_{E} W\left(1-\mathrm{RH}^{-\alpha S}\right) q_{s}(T),
\end{aligned}
$$

where $L$ is latent heat of evaporation, $\rho_{a}$ surface air density, $C_{E}$ the transfer coefficient, $W$ surface wind speed, RH surface relative humidity, $S=T_{a}-T$ is surface stability parameter, $T$ and $T_{s}$ are total SST and SAT at $2 \mathrm{~m}$ in kelvin, $q_{s}$ is the saturation specific humidity following the Clausius-Clapeyron equation, $q_{s}(T-S)=$ $q_{s}(T) e^{-\alpha S}, \alpha=L /\left(R_{v} T^{2}\right) \sim 0.06 \mathrm{~K}^{-1}$, and $R_{v}$ the gas constant for water vapor.

Surface latent heat flux is a measurable physical quantity. In studying SST variations, however, it should not be treated as a single dynamical quantity but as a mixture of SST response and atmospheric forcing. For example, with a reduction in wind speed, the ocean responds by raising SST to release the same amount of latent heat flux if everything else remains the same. This windevaporation-SST adjustment illustrates the duality of surface evaporation as both an atmospheric forcing and ocean response. In general, we can decompose surface latent flux (3) into a Newtonian cooling,

$$
Q_{E}^{o}=\frac{\partial Q_{E}}{\partial T} T^{\prime}=\alpha \bar{Q}_{E} T^{\prime},
$$

and a residual that represents atmospheric forcing,

$$
Q_{E}^{a}=Q_{E}^{\prime}-Q_{E}^{o}
$$

Similarly we can further decompose $Q_{E}^{a}$ into wind speed, relative humidity, and stability effects, which are not directly tied to SST but are due to atmospheric adjustments. The wind effect, for example, may be obtained,

$$
Q_{E}^{w}=\frac{\partial Q_{E}}{\partial W} W^{\prime}=\frac{\bar{Q}_{E} W^{\prime}}{\bar{W}},
$$

which turns out to be quite influential in SST pattern formation.

For pattern formation in mixed layer temperature, we obtain from (1)

$$
0=\left(D_{o}+Q_{a}\right)-\alpha \bar{Q}_{E} T^{\prime} .
$$

This equation casts SST pattern formation as a forced response problem. SST variations may arise from ocean circulation change, $D_{o}$, and atmospheric forcing via radiative and turbulent fluxes, $Q_{a}=\left(Q_{S}+Q_{L}\right)-Q_{H}-$ $Q_{E}^{a}$. Here sensible heat flux, $Q_{H}=-c_{p} \rho_{a} C_{H} W S$, has been included as atmospheric forcing $\left(c_{p}\right.$ is specific heat at constant pressure and $C_{H}$ the transfer coefficient for sensible heat). The SST dependency of surface evaporation acts as a damping to balance all forcing terms. The Newtonian cooling coefficient, $\alpha \bar{Q}_{E}$, represents the ocean's ability to limit SST warming by evaporation. It is proportional to mean evaporation, the latter varying from more than $150 \mathrm{~W} \mathrm{~m}^{-2}$ in the subtropics because of high wind and low $\mathrm{RH}$ to less than $50 \mathrm{~W} \mathrm{~m}^{-2}$ in the eastern Pacific cold tongue because of low SST, weak wind, and high RH. Such large spatial variations in $Q_{E}$ turn out to be important for SST pattern formation.

Similar surface flux decomposition has been applied to SST pattern formation in the equatorial Pacific (de Szoeke et al. 2007), the secular warming trend of the tropical Indian Ocean (Du and Xie 2008), and the rate of global precipitation increase under global warming (Richter and Xie 2008). The latter two studies show that surface relative humidity and stability both increase, acting to reduce evaporation and amplify the SST warming. Richter and Xie (2008) suggest that the increase in stability cools the surface atmosphere and forces $\mathrm{RH}$ to increase in analogy to sea fog formation. Takahashi (2009) 

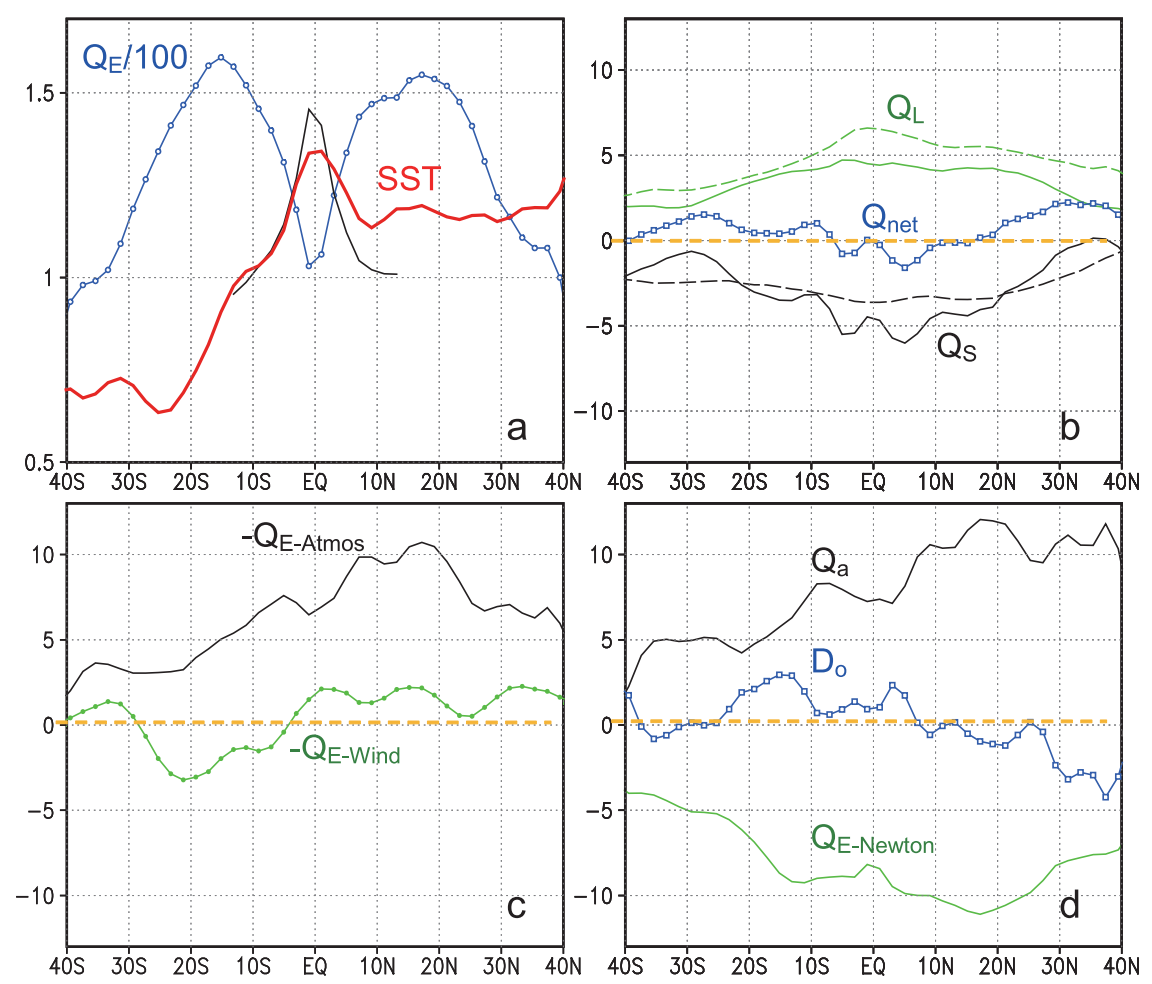

FIG. 1. Zonal- and annual-mean changes in CM2.1 A1B: (a) SST (red line, ${ }^{\circ} \mathrm{C}$ ) along with climatological latent heat flux $Q_{E}$ (blue line); (b) shortwave $\left(Q_{S}\right)$ and longwave $\left(Q_{L}\right)$ radiation at the sea surface (clear sky, dashed line); (c) atmospheric forcing component of latent heat flux $-Q_{E \text {-Atmos }}$ (black line) and its wind speed subcomponent $-Q_{E \text {-Wind }}$ (green line); and (d) atmospheric forcing $Q_{a}$ (black line) and Newtonian cooling $Q_{E \text {-Newton }}$ (green line) due to surface evaporation and ocean transport effect $D_{o}$ (blue line). Units for fluxes: $\mathrm{W} \mathrm{m}^{-2}$. The black line in (a) shows the SST response in Eq. (8) to $D_{o}+Q_{a}=9 \mathrm{~W} \mathrm{~m}^{-2}$, a value typical of oceanatmospheric forcing between $15^{\circ} \mathrm{S}$ and $15^{\circ} \mathrm{N}$.

shows that surface atmospheric stability increase results from reduced radiative cooling of the $\mathrm{ABL}$ as the atmospheric optical depth increases.

\section{Global survey of SST response patterns}

\section{a. Zonal-mean structure}

We begin by examining the zonal-mean SST response structure in CM (Fig. 1). Two features stand out: SST warming displays a sharp peak on the equator and is much stronger in the northern than southern subtropics. The former is the EER pattern of Liu et al. (2005). Figure 1 also shows various flux components obtained from the methodology developed in section 3 . Neither the radiative flux $\left(Q_{S}\right.$ and $\left.Q_{L}\right)$ nor ocean transport $\left(D_{o}\right)$ shows an equatorial peak. Net downward longwave radiation is positive everywhere because of increased GHG forcing and water vapor feedback. The broad tropical maximum in $Q_{L}$, for both clear and all-sky conditions, is consistent with that in water vapor increase. Surface shortwave radiation decreases due mostly to increased water vapor absorption (e.g., Trenberth and Fasullo 2009) as indicated by the clear-sky curve. In the equatorial region, the increase in convective clouds reduces solar radiation even more. The net radiative flux into the ocean is weakly negative near the equator and slightly positive in the subtropics. The net atmospheric flux $Q_{a}$ (including radiative flux and atmospheric contribution to turbulent flux) does not show an equatorial peak.

The equatorial peak in SST warming appears owing to meridional variations in the Newtonian cooling coefficient $\alpha \bar{Q}_{E}$. Mean latent heat flux (Fig. 1a) has a sharp minimum of $100 \mathrm{~W} \mathrm{~m}^{-2}$ at the equator compared to a subtropical peak of $160 \mathrm{~W} \mathrm{~m}^{-2}$. The meridional variation in $\bar{Q}_{E}$ is a strong pattern formation mechanism for SST,

$$
T=\frac{\left(D_{o}+Q_{a}\right)}{\left(\alpha \bar{Q}_{E}\right)} .
$$

A sharp equatorial peak forms even if the oceanatmospheric forcing function $\left(D_{o}+Q_{a}\right)$ is flat near the 
TABLE 1. Northern $\left(10^{\circ}-30^{\circ} \mathrm{N}\right)$ minus southern $\left(30^{\circ}-10^{\circ} \mathrm{S}\right)$ subtropical flux differences $\left(\mathrm{W} \mathrm{m}^{-2}\right)$ in ocean heat transport effect $D_{o}$, net radiation $Q_{R}$, atmospheric forcing $Q_{a}$, and Newtonian cooling $Q_{E}^{o}$ components of turbulent heat flux at the sea surface, all zonally averaged in CM2.1. The wind speed effect on latent heat flux, $-Q_{E}^{W}$, is a subcomponent of $Q_{a}$.

\begin{tabular}{cccccc}
\hline & $D_{o}$ & $Q_{R}$ & $Q_{a}$ & $-Q_{E}^{W}$ & $Q_{E}^{o}$ \\
\hline$\left.\Delta\right|_{30-10 \mathrm{~S}} ^{10-30 \mathrm{~N}}$ & -2.3 & -0.1 & 5.7 & 3.4 & 3.3 \\
\hline
\end{tabular}

equator. The black line in Fig. 1a shows the SST response according to (8) to a constant $\left(D_{o}+Q_{a}\right)=$ $9 \mathrm{~W} \mathrm{~m}^{-2}$, typical of ocean-atmospheric forcing between $15^{\circ} \mathrm{S}$ and $15^{\circ} \mathrm{N}$. A $\bar{Q}_{E}(y)$ variation from 100 to $160 \mathrm{~W} \mathrm{~m}^{-2}$ leads to a SST difference of $0.5^{\circ} \mathrm{C}$ between the equator and $15^{\circ} \mathrm{S} / \mathrm{N}$, slightly larger than the $0.3^{\circ} \mathrm{C}$ difference in $\mathrm{CM}$.

Liu et al. (2005) show that the equatorial peak in the Pacific SST warming response is common among the IPCC Fourth Assessment Report (AR4) models. They suggest that weak thermal damping due to weaker winds causes a stronger warming on the equator than in the subtropics (Seager and Murtugudde 1997). Knutson and Manabe (1995) point to zonal variations in mean SST as the major cause of variations in thermal damping and SST warming. Equation (8) generalizes that it is the mean evaporation that sets the Newtonian damping coefficient and forms an equatorial peak in SST warming. This is a good example of how the mean state helps shape spatial variations in SST warming. The mean evaporation pattern is determined by SST, wind speed, and relative humidity.

SST warming is greater by $0.5^{\circ} \mathrm{C}$ in the northern than southern subtropics, a substantial meridional asymmetry on a tropical-mean SST increase of $1^{\circ} \mathrm{C}$. Table 1 shows the northern - southern subtropical difference in various fluxes. Ocean circulation changes would somehow favor larger warming in the Southern Hemisphere. Of various components of atmospheric forcing, the wind effect on evaporation dominates, $3.4 \mathrm{~W} \mathrm{~m}^{-2}$ greater in the northern than southern subtropics, accounting for the north - south difference in Newtonian cooling. This is due to the intensification of the southeast trades by $0.3 \mathrm{~m} \mathrm{~s}^{-1}$ and a slight weakening of the northeast trades. Liu et al. (2005) note this meridional asymmetry and suggest the hemispheric difference in land-sea area as the cause. Our heat budget result shows the wind change as the cause of the larger warming over the northern subtropics, and section 6 will present evidence for interaction between SST and wind asymmetries. It is interesting to note that, in CCSM, this interhemispheric asymmetry in warming magnitude is much less than in $\mathrm{CM}$ despite the same land-sea distribution and a general increase in surface warming over land. The following sections explore the origin of interhemispheric difference in wind response.

\section{b. Horizontal distribution}

Figure 2 shows the annual-mean SST warming response in $\mathrm{CM}$ over the global $\left(60^{\circ} \mathrm{S}-60^{\circ} \mathrm{N}\right)$ ocean. The equatorial maximum is very pronounced in the Pacific but absent in both Atlantic and Indian Oceans. On the basin scale, wind speed change appears to be an important mechanism for SST variations (Fig. 2b). In the Southern Hemisphere subtropics, the southeast trades intensify in all three ocean basins, creating a meridional SST minimum $\left(<1^{\circ} \mathrm{C}\right)$. In the Northern Hemisphere, circulation changes are such that both northeast trades and the midlatitude westerlies weaken, maintaining a warming that is generally greater than $1^{\circ} \mathrm{C}$. The eastern tropical Pacific north of the equator is an exception where the wind speed actually increases, resulting in a local minimum in SST warming. The reduced wind speed south of Hawaii and in the tropical North Atlantic leads to locally enhanced warming. Indeed, the correlation between wind speed change and spatial deviations of SST warming (with the area mean subtracted) is -0.73 between $25^{\circ} \mathrm{S}$ and $20^{\circ} \mathrm{N}$, illustrating the wind speed modulation of SST warming in the tropics. In comparison, the spatial correlation between mean evaporation and SST warming is -0.11 , mostly due to the $Q_{E}$ minimum and SST peak in the equatorial Pacific.

In the midlatitude Northern Hemisphere, the SST warming displays narrow banded structures in the meridional direction. These banded structures are highly correlated with ocean heat transport anomalies, diagnosed from $D_{o}=-Q_{\text {net }}$, with the SST warming locally enhanced where ocean dynamical warming is positive ( $D_{o}>0$; Fig. 2a). Indeed, the correlation between $D_{o}$ and spatial variations in SST (with the area mean removed) is 0.83 and 0.96 over the North Pacific and Atlantic between $20^{\circ}$ and $60^{\circ} \mathrm{N}$, respectively. The ocean dynamical effect becomes important in the extratropics (north of $20^{\circ} \mathrm{N}$ ) because large gradients in the mean SST field enable ocean circulation changes to imprint readily on SST warming. The next section discusses regional ocean circulation changes in more detail.

Ocean dynamical effects can also be inferred by comparing CM2.1 with a simulation using a motionless ocean mixed layer (OML) model. Figure 3 shows the equilibrium response of the AM2.1 OML model to a $\mathrm{CO}_{2}$ doubling (note the different color scale compared to Fig. 2). The ocean mixed layer depth is $50 \mathrm{~m}$ everywhere and is forced by heat flux from the atmospheric model plus a prescribed monthly climatology of $Q$ flux. The $Q$ flux mimics the mean ocean heat transport effect 

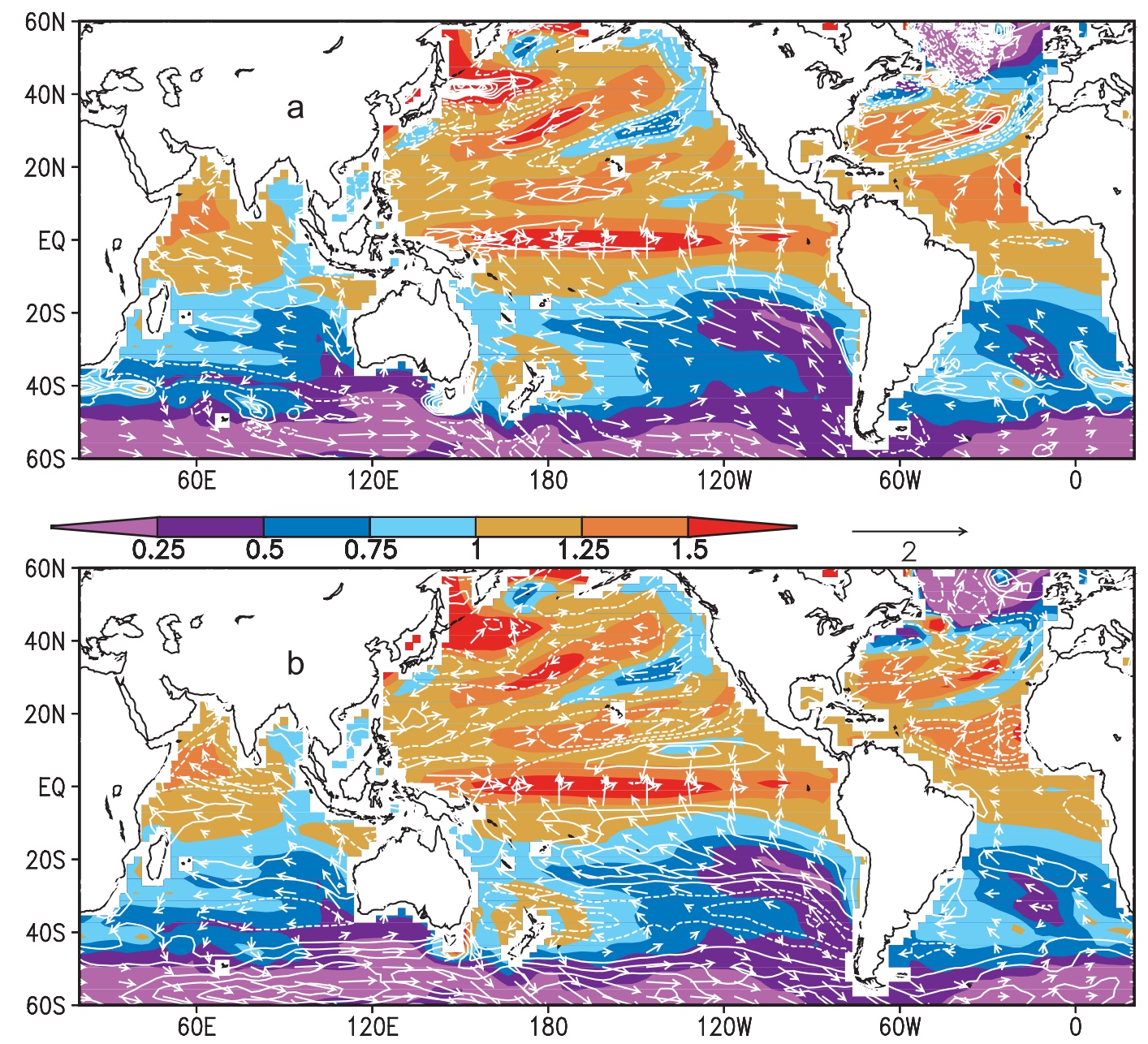

FIG. 2. Annual-mean changes in CM2.1 A1B: SST (color shaded, ${ }^{\circ} \mathrm{C}$ ) and surface wind velocity $\left(\mathrm{m} \mathrm{s}^{-1}\right.$ ), along with (a) ocean transport effect $\left[D_{o}=-Q_{\text {net }}\right.$, contour interval (CI) $\left.5 \mathrm{~W} \mathrm{~m}^{-2}\right]$ and (b) scalar wind speed $\left(\mathrm{CI}=0.1 \mathrm{~m} \mathrm{~s}^{-1}\right)$. Zero contours omitted for clarity.

and ensures that the model SST climatology is close to observations. Major differences between $\mathrm{CM}$ and AM OML are found in the subpolar North Atlantic and Southern Ocean, where the deep winter OML and ocean circulation adjustments keep SST warming subdued there in $\mathrm{CM}$ and large warming emerges without ocean dynamics in the OML simulation (Manabe et al. 1990).

The equatorial maximum in SST warming appears in both the Pacific ${ }^{1}$ and Atlantic with reduced warming in the subtropics, a meridional structure due to the variations in Newtonian damping $\left(\alpha \bar{Q}_{E}\right)$. This is especially clear in the subtropical Atlantic where the subtropical SST minimum on either side of the equator is associated with little change in wind speed. Leloup and Clement

\footnotetext{
${ }^{1}$ This is consistent with the OML simulation of Liu et al. (2005).
}

(2009) present a similar argument for reduced warming over the subtropical North Atlantic. In the South Pacific, the intensified southeast trades deepen the subtropical SST minimum. Over the subtropical North Pacific, on the other hand, the SST warming features a local maximum associated with a reduction in wind speed, consistent with the CM result that the SST asymmetry between the northern and southern subtropics is due to the asymmetry in wind speed change. Narrow banded SST structures in the meridional direction disappear in the OML simulation, confirming our earlier result that they are due to ocean circulation changes.

\section{Regional patterns}

Among many regional patterns in $\mathrm{CM}$, we choose for more in-depth discussion those that appear robust among models, judging from the multimodel ensemble-mean 

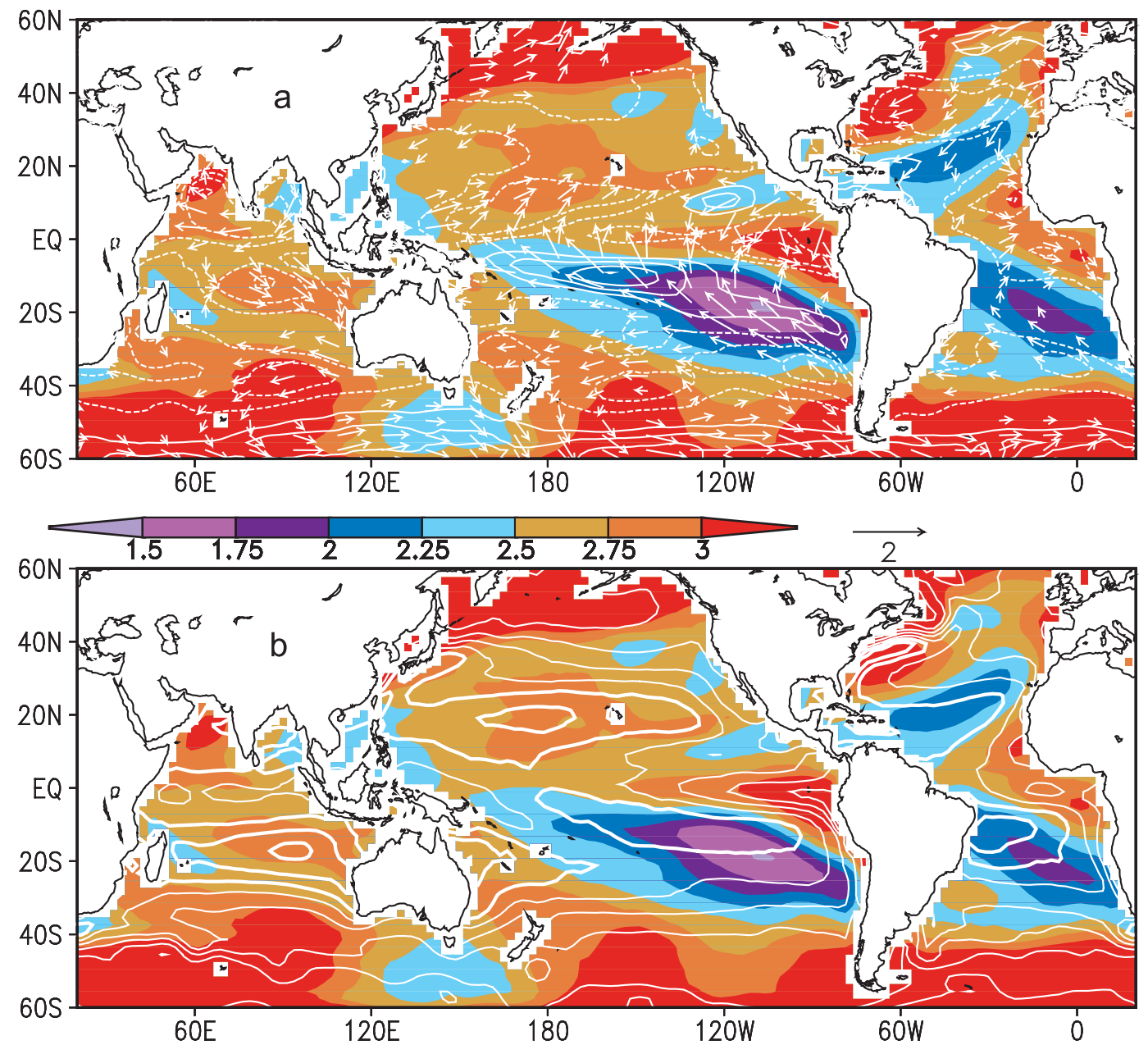

FIG. 3. Annual-mean changes in the $2 \times \mathrm{CO}_{2}$ simulation with AM2.1-OML: SST (color shaded, ${ }^{\circ} \mathrm{C}$ ): (a) surface wind velocity (vectors, $\mathrm{m} \mathrm{s}^{-1}$ ) and scalar speed (white contours, CI $0.2 \mathrm{~m} \mathrm{~s}^{-1}$; zero omitted) and (b) climatological latent heat flux (white contours, CI $25 \mathrm{~W} \mathrm{~m}^{-2}$; thick $\geq 150 \mathrm{~W} \mathrm{~m}^{-2}$ ).

maps (e.g., Fig. 10.9 of Meehl et al. 2007; Fig. 1 of Lu et al. 2008). These patterns are found in the equatorial Pacific, equatorial Indian Ocean, subtropical South Pacific, and midlatitude North Atlantic and Pacific.

\section{a. Equatorial Pacific}

Equatorial Pacific warming is flat in the east-west direction with a broad maximum in the central basin (Fig. 4a). The zonal structure of the equatorial warming is affected by a myriad of processes. The mean upwelling/ entrainment brings up pristine thermocline water, reducing surface warming in the eastern equatorial Pacific (upwelling damping, Clement et al. 1996; Cane et al. 1997). On the other hand, the Walker circulation slows down under global warming (Vecchi et al. 2006) with westerly wind anomalies in the equatorial Pacific (Fig. 4a). The westerly anomalies deepen the thermocline in the east, acting to warm the eastern ocean (thermocline feed- back; Vecchi and Soden 2007b). Thus, the upwelling damping and thermocline feedback effects are both expected to be large in the east but opposite in sign. Their net effect as measured by $D_{o}$ is nearly zero in the east equatorial Pacific (Fig. 4b). The upwelling damping effect may weaken into the future as the ventilation brings midlatitude SST warming to the equatorial thermocline (Liu 1998).

Along the equator, the ocean dynamical warming is large in the west at $\sim 5 \mathrm{~W} \mathrm{~m}^{-2}$. The westerly wind anomalies drive eastward anomalous currents near the equator, and the resultant warm advection explains much of the zonal variations in $D_{o}$ (Fig. 4c; DiNezio et al. 2009). The ocean dynamical warming (owing to the eastward advection) alone, however, does not explain the zonal structure of SST warming. The evaporative damping coefficient $\bar{Q}_{E}$-large in the west and small in the easttransforms an eastward-decreasing $D_{o}$ into a nearly 


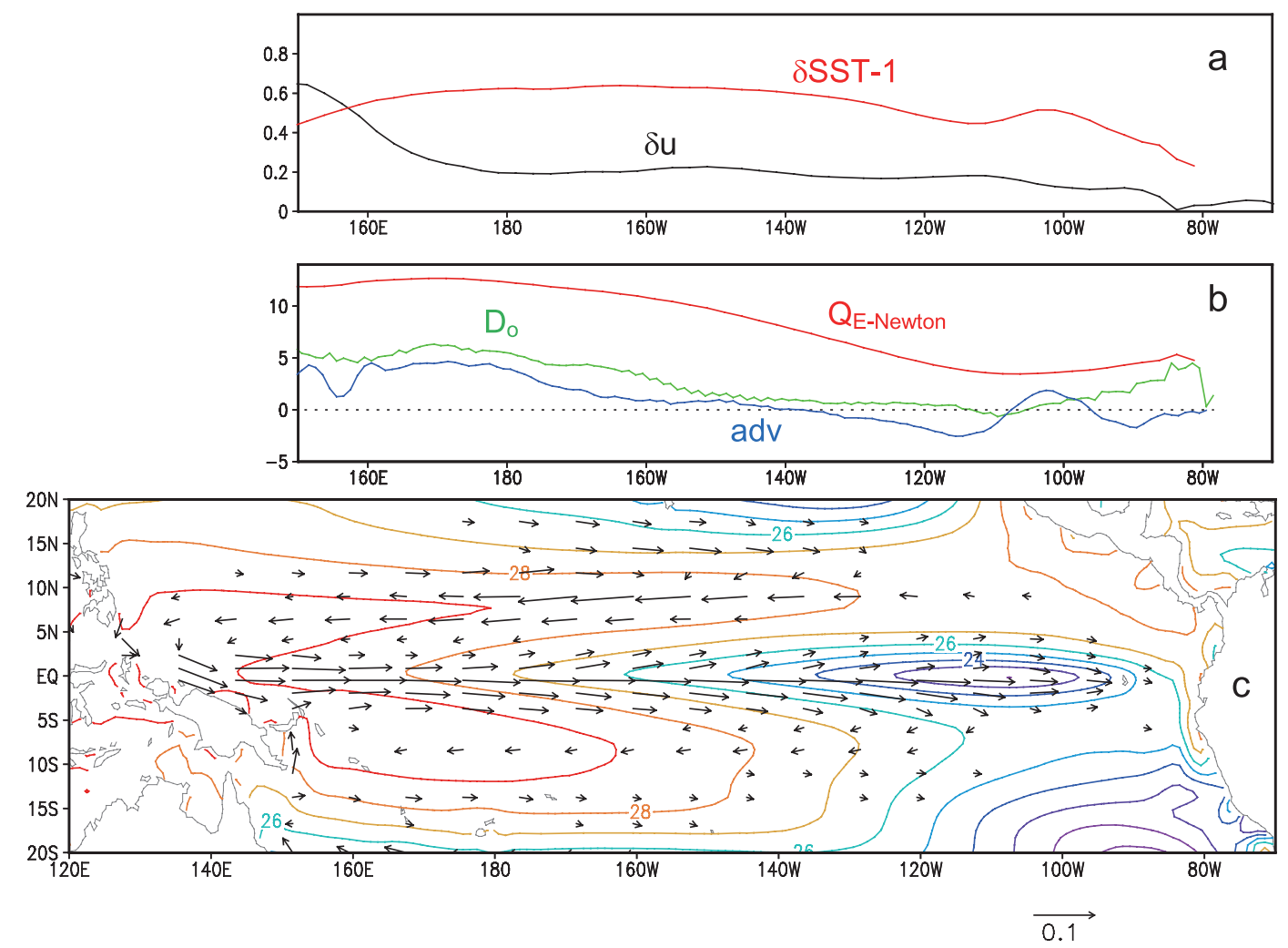

FIG. 4. Annual-mean changes in CM2.1 A1B on the equator $\left(2.5^{\circ} \mathrm{S}-2.5^{\circ} \mathrm{N}\right)$ : (a) SST (red line, $\left.{ }^{\circ} \mathrm{C}\right)$ and zonal wind velocity (black line, $\mathrm{m} \mathrm{s}^{-1}$ ) and (b) horizontal advection integrated over the mixed layer (adv, blue line), the total ocean heat transport effect $\left(D_{o}=-Q_{\text {net }}\right.$, green line), and the Newtonian cooling component (red line) of surface latent heat flux, all in $\mathrm{W} \mathrm{m}^{-2}$. (c) Changes in current velocity $\left(\mathrm{m} \mathrm{s}^{-1}\right)$ at $25 \mathrm{~m}$ superimposed on the climatological $\operatorname{SST}\left({ }^{\circ} \mathrm{C}\right)$.

zonal-uniform warming pattern in SST, as expected from Eq. (8). This evaporative damping effect is most clearly illustrated in the AM-OML simulation (Fig. 3). Without the ocean dynamical effect, the equatorial warming strengthens toward the east, roughly following the $1 / \bar{Q}_{E}$ function.

Figure 5 shows the longitude-time section of SST warming on the equator. The equatorial Pacific warming displays a pronounced annual cycle, peaking in May with a maximum of $2.3^{\circ} \mathrm{C}$ and reaching a minimum of less than $1^{\circ} \mathrm{C}$ in October. $\mathrm{CM}$ simulates the annual cycle in climatological SST, with a maximum in April and minimum in September (Wittenberg et al. 2006). The May-October difference in GHG-induced warming is $1.3^{\circ} \mathrm{C}$, as large as the annual-mean warming, representing a strengthening of the equatorial annual cycle. Timmermann et al. (2004) diagnose the mixed layer heat budget and show that the annual cycle in mean upwelling is the cause (Clement et al. 1996). The climatological upwelling is strong during the cool season of AugustOctober, and the increased damping reduces the SST response to the GHG forcing. With zonal wind change varying little in season, this upwelling damping mechanism of Clement et al. appears to dominate the seasonal cycle in SST warming. A similar annual cycle is found over the equatorial Atlantic in the climatology and SST response to GHG increase. The annual range of SST warming is much weaker at $\sim 0.5^{\circ} \mathrm{C}$ in the Atlantic. Such an annual cycle in SST warming is not found in the AM OML simulation without ocean dynamics (not shown), supporting the upwelling damping mechanism.

The GHG-induced pattern of tropical Pacific SST warming is often characterized as El Niño-like in that it peaks on the equator (Meehl et al. 2006). However, there are a number of important differences in the associated atmospheric responses over the tropical Pacific to global warming and El Niño. For example, westerly wind anomalies extend across the entire equatorial $\mathrm{Pa}$ cific in response to global warming (recall Fig. 2) but are limited to the western half of the basin in El Niño (Wittenberg et al. 2006). The anomalous westerlies are also more narrowly confined to the equator in global warming compared to El Niño. El Niño and GHGinduced warming in the equatorial Pacific differ in 


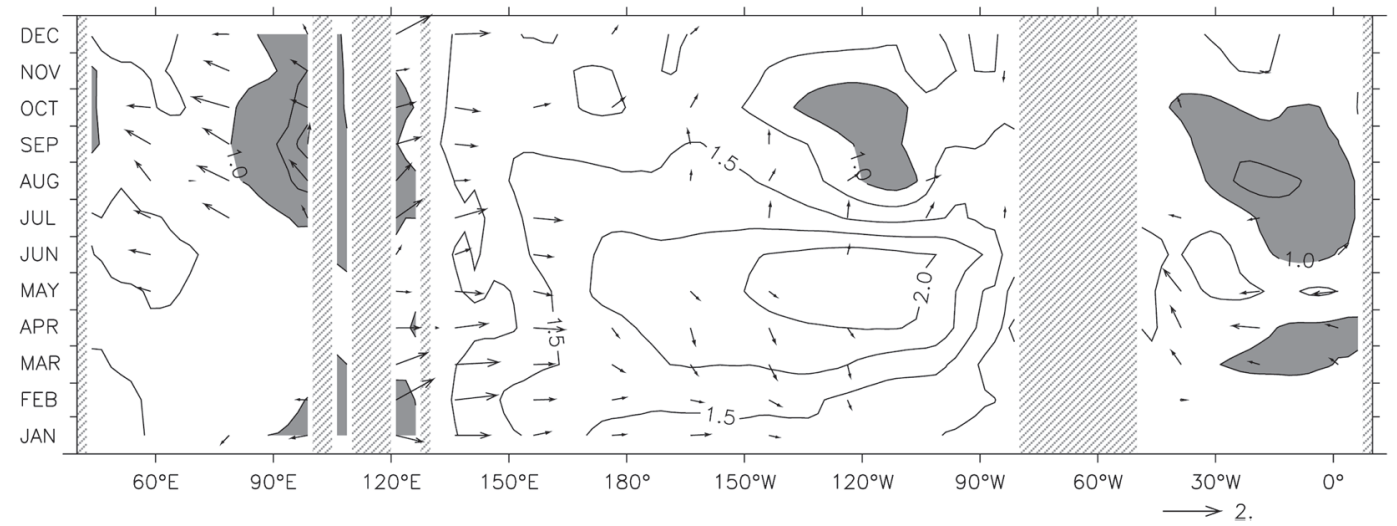

FIG. 5. Longitude-time section changes in SST $\left(\mathrm{CI} 0.25^{\circ} \mathrm{C}\right.$, shading $\left.<1^{\circ} \mathrm{C}\right)$ and surface wind velocity $\left(\mathrm{m} \mathrm{s}^{-1}\right)$ on the equator in CM2.1 A1B.

seasonality: the former peaks in December while the latter peaks in May. Off-equatorial atmospheric circulation also responds differently. During El Niño, sea level pressure in the tropical South Pacific decreases as part of the Southern Oscillation (e.g., Deser et al. 2006), but it increases in global warming to intensify the southeast trades. The Aleutian low in the North Pacific deepens during El Niño but slightly weakens, if anything, in global warming (Fig. 2).

The GHG-induced warming and El Niño also differ in mechanism. Although thermocline feedback is key for El Niño, removing interactive ocean dynamics in the OML $2 \times \mathrm{CO}_{2}$ simulation renders the equatorial SST warming more El Niño-like than in $\mathrm{CM}$, resulting in an eastward intensification due to the eastward decrease in evaporative damping. Four mechanisms-upwelling damping, thermocline feedback, zonal advection, and evaporative damping-are involved in zonal SST pattern formation under global warming along the equator. Not surprisingly, models display a great diversity in the east-west gradient of SST warming along the equator (Liu et al. 2005) as the relative importance of these mechanisms varies among models.

\section{b. Tropical Indian Ocean}

In the equatorial Indian Ocean, SST warming is nearly zonally uniform at $1.25^{\circ} \mathrm{C}$ except for July-November when it is significantly reduced in the east by $0.5^{\circ} \mathrm{C}$ (Fig. 5). Figure 6 shows the horizontal distributions during August-October of SST, precipitation, surface wind, and sea surface height (SSH) over the tropical Indian Ocean. The SST warming is reduced to $0.5^{\circ} \mathrm{C}$ off the Indonesian coast, whereas it is amplified to $1.5^{\circ} \mathrm{C}$ in the northwest equatorial basin. The sharp SST gradients force precipitation to decrease (increase) in the southeast (northwest) equatorial basin, driving strong southeasterly wind anomalies $\left(>1 \mathrm{~m} \mathrm{~s}^{-1}\right)$ on the equator. On the equator, the easterly winds shoal the thermocline in the east, helping cool SST there via upwelling. The patterns of ocean-atmospheric anomalies are indicative of the Bjerknes feedback and reminiscent of the Indian Ocean dipole (IOD).

The IOD is a major mode of climate variability over the tropical Indian Ocean, strongly locked in phase to the July-October season when the southeasterly alongshore winds induce upwelling on the Indonesian coast and permit Bjerknes feedback (Saji et al. 1999). For recent reviews, see Chang et al. (2006) and Schott et al. (2009) and references therein. Surprisingly, the shoaling thermocline and enhanced thermocline feedback in the eastern equatorial Indian Ocean do not lead to an increase in IOD interannual variability because atmospheric feedback weakens in response to strengthened tropospheric stability (Zheng et al. 2010).

Many models, including CM and CCSM, display a tendency to develop an IOD-like warming pattern during the Sumatra upwelling season (July-October) with the shoaling thermocline in the east (Vecchi and Soden 2007b; Du and Xie 2008). There are several reasons for this tendency to develop. The slowdown of the Walker circulation in global warming (Vecchi et al. 2006) is associated with easterly wind anomalies over the equatorial Indian Ocean. Such anomalous easterlies, albeit weak, are indeed present in the AM OML simulation (Fig. 3) and may be amplified by the Bjerknes feedback during the IOD season. Alternatively, the mean upwelling off the Indonesian coast during the July-October season reduces the local warming, initiating a zonal SST gradient and Bjerknes feedback (Meng et al. 2009, manuscript submitted to Adv. Atmos. Sci.).

Over the equatorial Indian Ocean, SSH anomalies are consistent with ocean wave response to easterly wind change, with an upwelling Kelvin wave wedge in the east and downwelling Rossby waves with an off-equatorial 

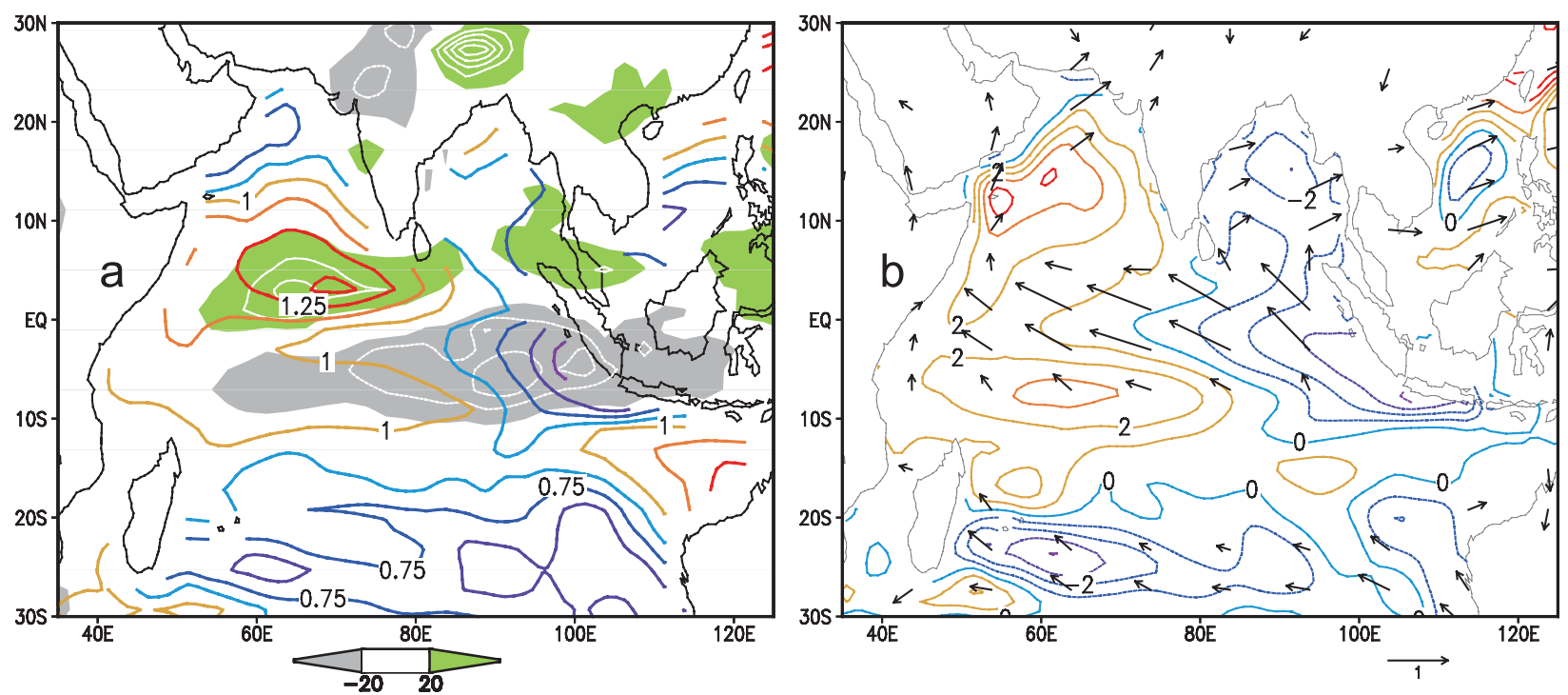

FIG. 6. August-October changes in CM2.1 A1B: (a) SST (color, CI $0.125^{\circ} \mathrm{C}$ ) and precipitation (green/gray shade and white contours, CI $20 \mathrm{~mm} \mathrm{month}^{-1}$ ) and (b) sea surface height $(\mathrm{CI} 1 \mathrm{~cm})$ and surface wind velocity $\left(\mathrm{m} \mathrm{s}^{-1}\right)$.

peak on either side of the equator (Fig. 6b). The thermocline deepens in the tropical southwest Indian Ocean where the mean thermocline is shallow and allows thermocline changes to affect SST readily (Xie et al. 2002; Schott et al. 2009). Indeed, the deepened thermocline acts to warm SST with $D_{o}>5 \mathrm{~W} \mathrm{~m}^{-2}$ (Fig. 2a). Despite this ocean dynamical warming, the south Indian Ocean is much cooler relative to the tropical-mean warming than in the AM OML simulation (cf. Figs. 2 and 3). This may seem paradoxical, but a close comparison indicates that the SST difference between these runs is consistent with their difference in surface wind speed. In the AM OML run, the large warming in the tropical south Indian Ocean is associated with weakened southeast trades, while in CM the southeast trades intensify.

The reduced warming in $\mathrm{CM}$ in the subtropical south Indian Ocean may originate from the Southern Ocean, where large differences are found between AM OML and CM. In the Southern Ocean the SST warming is substantially weaker in CM because of upwelling and bottom-water formation in the mean (Manabe et al. 1990). These results lead us to suggest that WES feedback helps propagate the Southern Ocean cooling equatorward in CM. The equatorial westward propagation due to WES feedback, sometimes called fingerprinting mechanism, is important for extratropical-tropical teleconnection in interannual variability (Vimont et al. 2003; Wu et al. 2007). Kang et al. (2008) recently suggest an alternative, energetics argument for such a teleconnection. The Southern Ocean cooling owing to ocean dynamical effects may explain weaker SST warming in the southern than in the northern subtropics via these teleconnection mechanisms from the extratropics to the tropics.

\section{c. North Atlantic}

The SST warming over the North Atlantic features distinct banded structures that slant in a northeastsouthwest direction (Fig. 7). These bands are typically $5^{\circ}$ wide and of basin scale in length. The SST difference between neighboring warm and cool bands is about $0.5^{\circ} \mathrm{C}$ on a background warming of $1.25^{\circ} \mathrm{C}$ in the subtropics. Without exception, warm bands are collocated with northeastward current anomalies and cool bands are collocated with anomalous southwest flows, indicative of advection of the southwestward SST gradients in the mean by anomalous currents (Fig. 7a). This advection mechanism is consistent with the changes in net surface flux, which act to dampen the banded structures in SST. Such narrow bands $\left(\sim 5^{\circ}\right.$ wide) are not present in the AM-OML simulation. Over the broad subpolar North Atlantic north of $45^{\circ} \mathrm{N}$, SST anomalies are actually negative, associated with strong dynamical cooling resulting from changes in ocean circulation.

The narrow bands of alternating sign in the midlatitude/ subtropical North Atlantic illustrate that changes in ocean dynamical fields can imprint strongly on SST warming. A detailed analysis of the cause of circulation changes is ongoing and will be presented elsewhere (H. Seo 2009, personal communication). A brief summary follows. The bands of alternating southwest/northeastward currents in $\mathrm{CM}$ are due to changes in mode waters, thick layers of nearly vertical uniform water properties in the main thermocline. Indeed, the southwest slant of these bands 

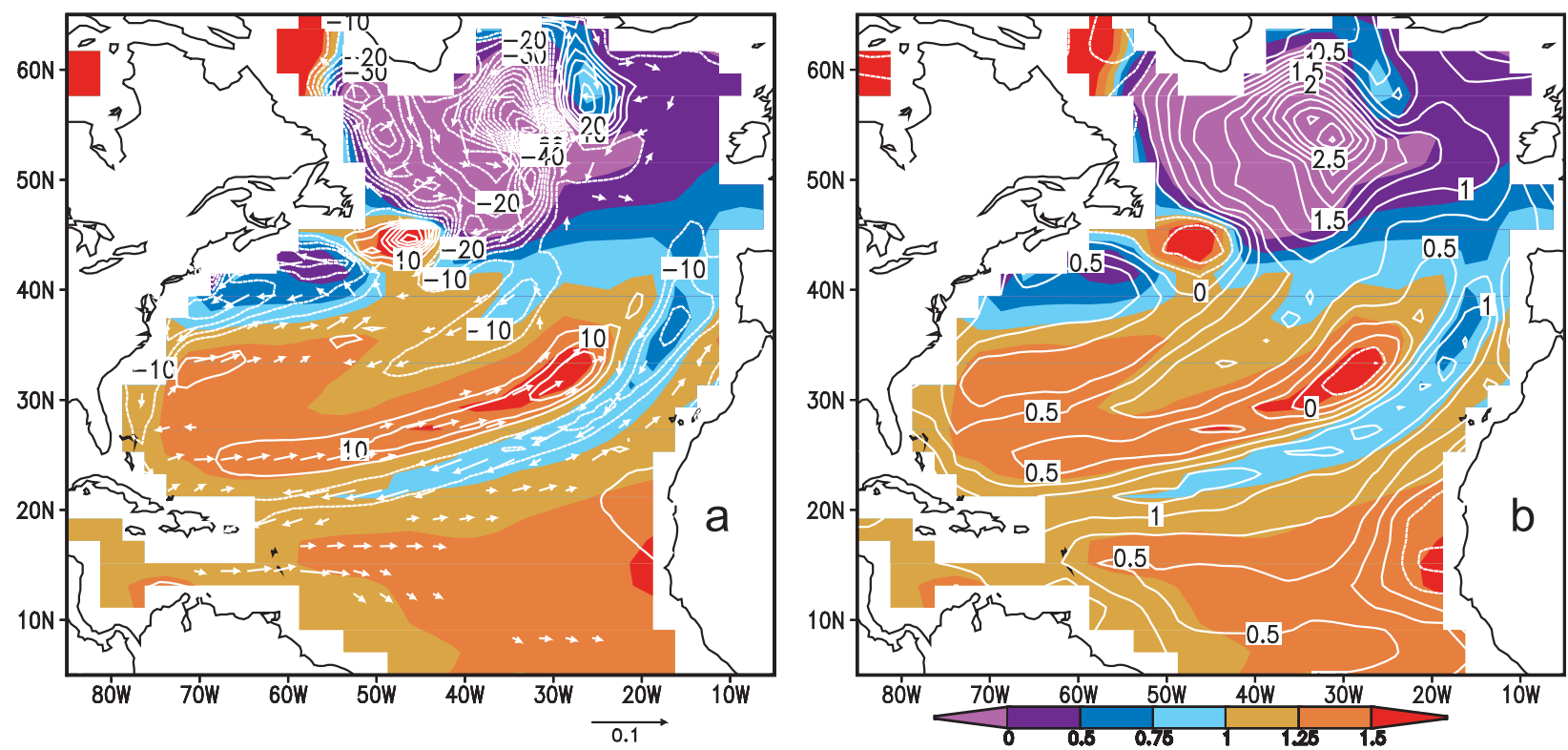

FIG. 7. Annual-mean changes in CM2.1 A1B: SST (colored, $\left.{ }^{\circ} \mathrm{C}\right) ;\left(\right.$ a) ocean current velocity $\left(\mathrm{m} \mathrm{s}^{-1}\right.$ ) at $25 \mathrm{~m}$ and ocean heat transport effect $\left(D_{o}=-Q_{\text {net }}\right.$; white contours, CI $5 \mathrm{~W} \mathrm{~m}^{-2}$ with the zero contours omitted) and (b) surface RH (white, CI $0.25 \%$ ).

of anomalous currents is consistent with changes in mode water ventilation in the subtropical gyre. Xie et al. (2000) discuss interdecadal changes in North Pacific mode waters and show that they can be the dominant mechanism for ocean temperature variability in the central subtropical gyre. Gnanadesikan et al. (2006) analyze a CM control simulation under constant GHG forcing and show that the model produces spuriously thick mode waters in the density range $26.5-27.5 \sigma_{\theta}$, possibly associated with the southward recirculation of the model North Atlantic Current south of the British Isles. It is quite remarkable that changes in North Atlantic water mass ventilation have significant effects on SST in the subtropics. We note that the southernmost narrow band of SST sweeps through the main development region of North Atlantic hurricanes.

The narrow SST bands leave clear signatures in the surface atmosphere. Figure $7 \mathrm{~b}$ is an example, superimposing changes in surface relative humidity and SST. The width of SST bands is much smaller than the scales of atmospheric adjustments (e.g., the radius of deformation). As a result, over a cool SST band, surface atmospheric stability increases, and this surface cooling of the atmosphere acts to increase surface relative humidity, much as in sea fog formation. Over a warm SST band, the opposite happens, with a small increase or even a decrease in RH. Such a RH response dampens the banded structure of SST. The RH difference between warm and cool bands is about $1 \%$, equivalent to a $5 \%$ change in surface evaporation or $5 \mathrm{~W} \mathrm{~m}^{-2}$. In comparison, the SST difference between neighboring
SST bands is about $0.5^{\circ} \mathrm{C}$, resulting in a latent heat flux difference of $3 \mathrm{~W} \mathrm{~m}^{-2}$. This RH response to SST bands is consistent with the hypothesis of Richter and Xie (2008) that, in global warming, the radiative-induced increase of surface stability causes RH to increase. The RH changes over the North Atlantic may be decomposed into basin and narrow $\left(5^{\circ}\right)$ scales. On the basin scale, the RH increase is forced by GHG increase and a positive feedback for SST warming. On the narrow $\left(5^{\circ}\right)$ scale, the RH increase is forced by a relative cooling in SST and acts as a negative feedback for the narrow cool SST band. On both scales, the RH increase is due to sea surface cooling of the atmosphere.

Similar narrow banded structures are found in SST warming over the midlatitude North Pacific (Fig. 2a), collocated with bands of $D_{o}$ change owing to changes in mode water ventilation (F. Kobashi 2009, personal communication) and with $\mathrm{RH}$ change associated with atmospheric stability effects.

\section{6. $\operatorname{CCSM3}$}

Figure 8 shows 50 -yr changes in SST and surface wind from the CCSM A1B, 30-member ensemble simulation. Overall, the spatial variations in SST warming from CCSM are similar to CM. Specifically, the Pacific warming features a local maximum on the equator where the evaporative Newtonian damping is at minimum. In the equatorial Pacific, large westerly wind anomalies and large ocean dynamical warming $\left(D_{o}>10 \mathrm{~W} \mathrm{~m}^{-2}\right)$ are found in the west, causing the SST warming to strengthen 


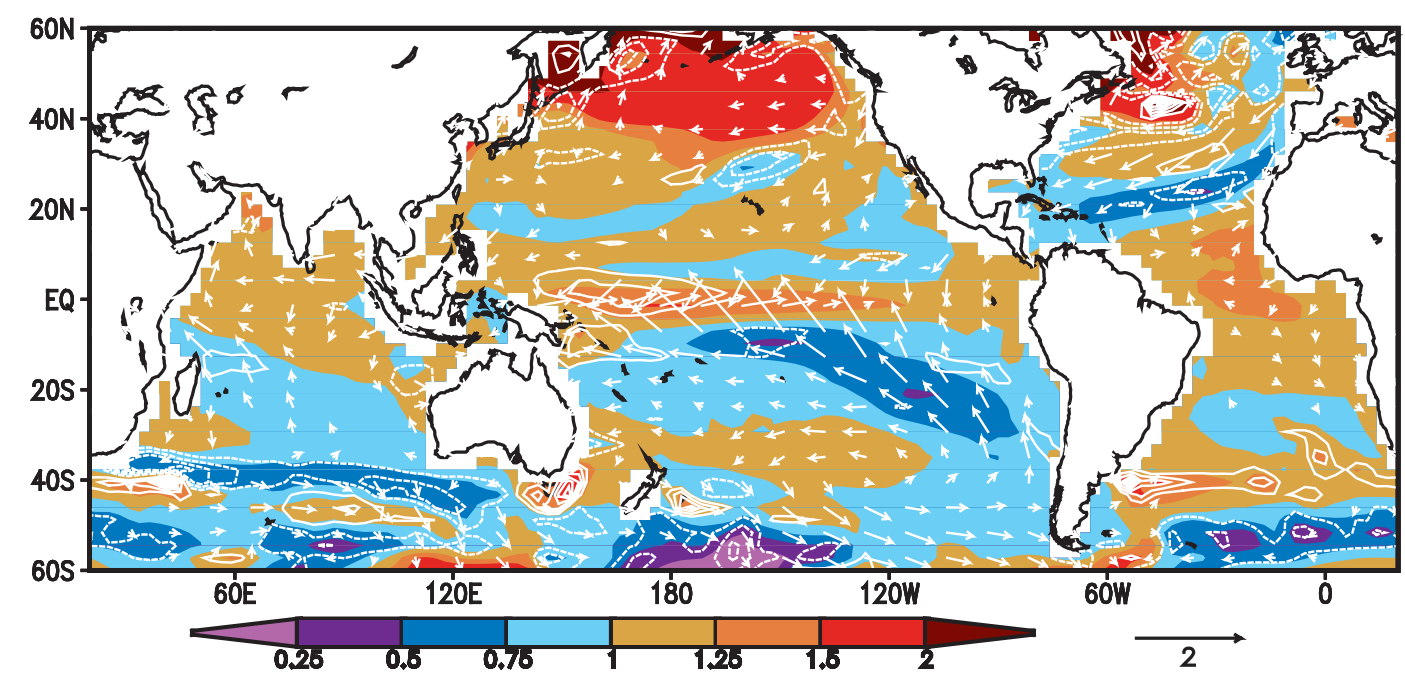

FIG. 8. Annual-mean changes in CCSM3 A1B: SST (color shading, $\left.{ }^{\circ} \mathrm{C}\right)$, surface wind velocity $\left(\mathrm{m} \mathrm{s}^{-1}\right)$, and ocean heat transport effect ( $D_{o}$; white contours, CI $5 \mathrm{~W} \mathrm{~m}^{-2}$ with zero omitted).

slightly westward. In the Pacific, the SST warming is larger in the northern than southern subtropics, an interhemispheric asymmetry consistent with wind speed change. An IOD-like pattern appears in the equatorial Indian Ocean during July-October (not shown), with reduced SST warming in the east compared to the west in association with anomalous easterlies and the Bjerknes feedback. In the northern extratropics, narrow banded structures are prominent in the SST warming pattern, similar to those in CM. These banded SST structures are positively correlated with the ocean heat transport effect (Table 2). Similar narrow banded SST structures associated with ocean circulation changes appear in the Southern Ocean, especially the Indian and Atlantic sectors; these features are less apparent in CM.

In general, spatial variations in SST warming are weaker in amplitude in CCSM than in CM. For example, the equatorial maximum in the western Pacific is $1.4^{\circ} \mathrm{C}$ in CCSM compared to $1.7^{\circ} \mathrm{C}$ in $\mathrm{CM}$, and the southeast Pacific minimum is about $0.5^{\circ} \mathrm{C}$ in CCSM compared to $0.2^{\circ} \mathrm{C}$ in $\mathrm{CM}$. Also, the difference between the global northern and southern subtropics is less pronounced in CCSM compared to $\mathrm{CM}\left(0.1^{\circ} \mathrm{C}\right.$ compared to $\left.0.4^{\circ} \mathrm{C}\right)$. The latter interhemispheric difference is almost nonexistent in the Atlantic basin in CCSM.

\section{Southeast Pacific cool patch}

The cool patch in the subtropical southeast Pacific with a northwestward extension is a robust pattern in CM (Fig. 2a) and CCSM (Fig. 8), as well as in the multimodel ensemble mean (Fig. 10.9 of Meehl et al. 2007). The cool patch is collocated with the intensified southeast trades, suggestive of a WES feedback between them. Indeed, ocean heat transport is small in the main part of the cool patch, and the southeast Pacific cool patch is simulated in OML simulations with both AM2.1 (Fig. 3) and CAM3 (not shown).

To shed light on the formation of this SST pattern, we make use of complementary experiments with the CCSM atmospheric model component CAM3. In these experiments, CAM is forced separately with either the direct A1B radiative forcing (SSTs fixed at 2000 values, termed the $\delta$ RAD run) or the monthly SST field for 2000-60 from the CCSM A1B ensemble simulation (direct radiative forcing fixed at 2000 values, termed the $\delta$ SST run). An additional experiment in which CAM is forced with both direct $\mathrm{A} 1 \mathrm{~B}$ radiative forcing and monthly SST evolution from the CCSM A1B ensemble simulation reproduces the CCSM surface wind changes quite well (Fig. 9c). Similar results are found for the second half of the twentieth century for which observations are available for comparison (Deser and Phillips 2009).

Over the southeast Pacific, the change in radiative forcing strengthens the southeast trades in the band $20^{\circ}-$ $30^{\circ} \mathrm{S}$ (Fig. 9b), whereas the SST-induced intensification

TABLE 2. Correlations with SST deviations $T *$ from area means: changes in precipitation $P$, scalar wind speed $W$, and ocean heat transport effect $D_{o}$ between $20^{\circ}$ and $60^{\circ} \mathrm{N}$ in the CM2.1 and CCSM3. Scalar wind speed is not available in CCSM3 output.

\begin{tabular}{lcccc}
\hline \hline & $\begin{array}{c}\left(T^{*}, P\right) \\
20^{\circ} \mathrm{S}-20^{\circ} \mathrm{N}\end{array}$ & $\begin{array}{c}\left(T^{*}, W\right) \\
25^{\circ} \mathrm{S}-20^{\circ} \mathrm{N}\end{array}$ & $\begin{array}{c}\left(T^{*}, D_{o}\right) \\
\text { Pacific }\end{array}$ & $\begin{array}{c}\left(T^{*}, D_{o}\right) \\
\text { Atlantic }\end{array}$ \\
\hline CM2.1 & 0.56 & -0.73 & 0.83 & 0.96 \\
CCSM3 & 0.61 & - & 0.33 & 0.39 \\
\hline
\end{tabular}


(a) CAM 3.0 forced with SST

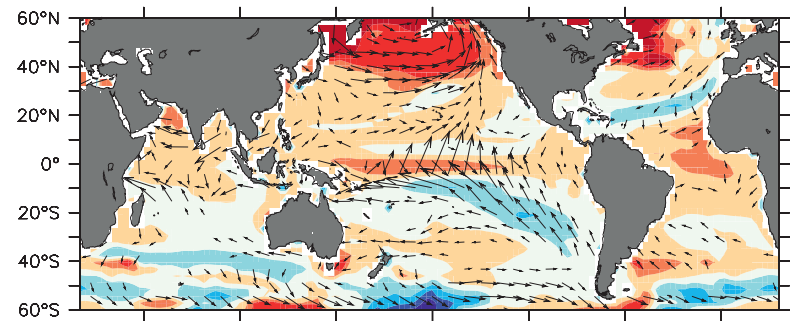

(b) CAM 3.0 forced with RAD

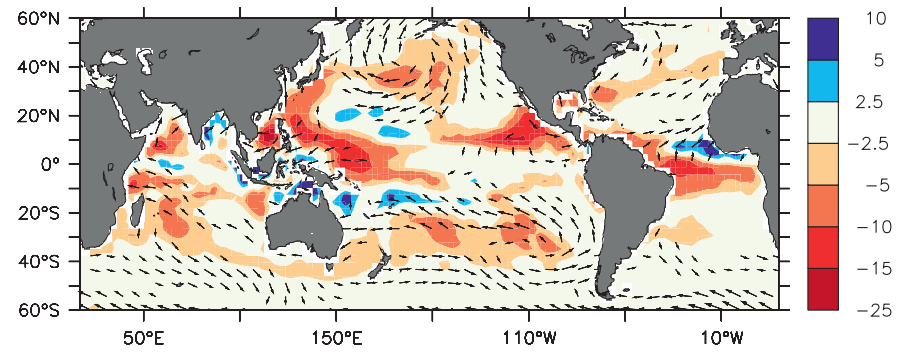

(c) CAM 3.0 forced with SST and RAD

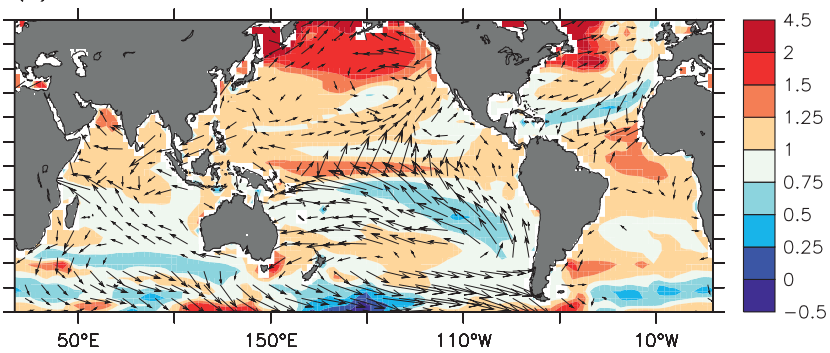

FIG. 9. Annual-mean response (2051-60 minus 2001-10) of surface wind velocity $\left(\mathrm{m} \mathrm{s}^{-1}\right)$ in CAM3 to (a) SST and (b) A1B RAD forcing only and (c) the combined forcing. Superimposed are changes in (a),(c) SST $\left({ }^{\circ} \mathrm{C}\right)$ and (b) precipitation $\left(\mathrm{mm} \mathrm{month}{ }^{-1}\right)$. A1B forcing includes ozone, which affects both shortwave and longwave radiation. of the southeast trades is nearly collocated with the cool patch (Fig. 9a). This supports a possible fingerprinting mechanism in which the direct $\delta \mathrm{RAD}$ effect triggers the initial SST cooling by strengthening the southeast trades and then WES feedback kicks in to propagate the coupled perturbation equatorial westward (Vimont et al. 2003, 2009; Wu et al. 2007). The wind response to $\delta \mathrm{RAD}$ and $\delta$ SST requires further study, but may be related to the expansion of the Hadley circulation (Williams and Bryan 2006; Lu et al. 2007) and changes in transient eddy properties (Lu et al. 2008; Chen et al. 2008).

\section{Effects of SST patterns on precipitation}

We now examine SST effects on precipitation change. Figures 10a,c show the SST and precipitation changes in $\mathrm{CM}$ and CCSM. In general, increased (decreased) precipitation corresponds with local maxima (minima) of SST warming. Over the tropical Pacific, for example, the equatorial maximum in SST warming apparently anchors a band of strong precipitation increase in both $\mathrm{CM}$ (Fig. 10a) and CCSM (Fig. 10c). South of the equator, on the other hand, precipitation decreases as SST warming weakens. The strong SST warming in the tropical North Atlantic results in a precipitation increase, whereas over the South Atlantic a band of decreased precipitation is associated with a cool patch in SST. The positive correlation between SST and precipitation is also apparent over the subtropical North Pacific, especially in CM. Overall, the correlation between precipitation and SST deviation from the tropical mean within $20^{\circ} \mathrm{S}-20^{\circ} \mathrm{N}$ is 0.56 and 0.61 in CM and CCSM, respectively.

Since there are little spatial variations in uppertropospheric warming, changes in gross moist instability are dominated by variations in surface humidity (appendix). In coupled simulations, percentage change in surface humidity is highly correlated with local SST (Fig. 11), yielding a regression relation

$\frac{q_{a}}{\bar{q}_{a}}=a T+b, \quad$ with $\quad a=0.052$ and $b=0.026$.

The SST proportionality $a$ is close to the theoretical value $\left(\alpha=0.06 \mathrm{~K}^{-1}\right)$ from the Clausius-Clapeyron equation. At $T=0, q_{a}$ does not vanish in (9), an effect due to advection and diffusion of moisture increase from surroundings regions.

Spatial variations in SST warming have been overlooked in the literature on future precipitation projections. Discussion in the literature tends to focus on the increase in humidity gradients associated with a uniform SST warming owing to Clausius-Clapeyron effects. Atmospheric model simulations of the response to uniform SST warming are routinely conducted in climate feedback studies (Cess et al. 1990). Figures 10b,d show precipitation change in response to a uniform SST increase of $2 \mathrm{~K}$ in AM2.1 and CAM2. These so-called Cess experiments serve as a good baseline against which we compare coupled simulations to evaluate the effect of SST warming patterns. Rainfall response is weak to atmospheric constituent change without SST anomalies (cf. Fig. 9b; Allen and Ingram 2002; Deser and Phillips 2009).

In the Cess runs, a uniform SST increase results in precipitation change with spatial variations. Rainfall increases along major climatological rainbands (Figs. 10b,d) including the South Pacific convergence zone (SPCZ) and the ITCZ of all three ocean basins, except for the Indian 


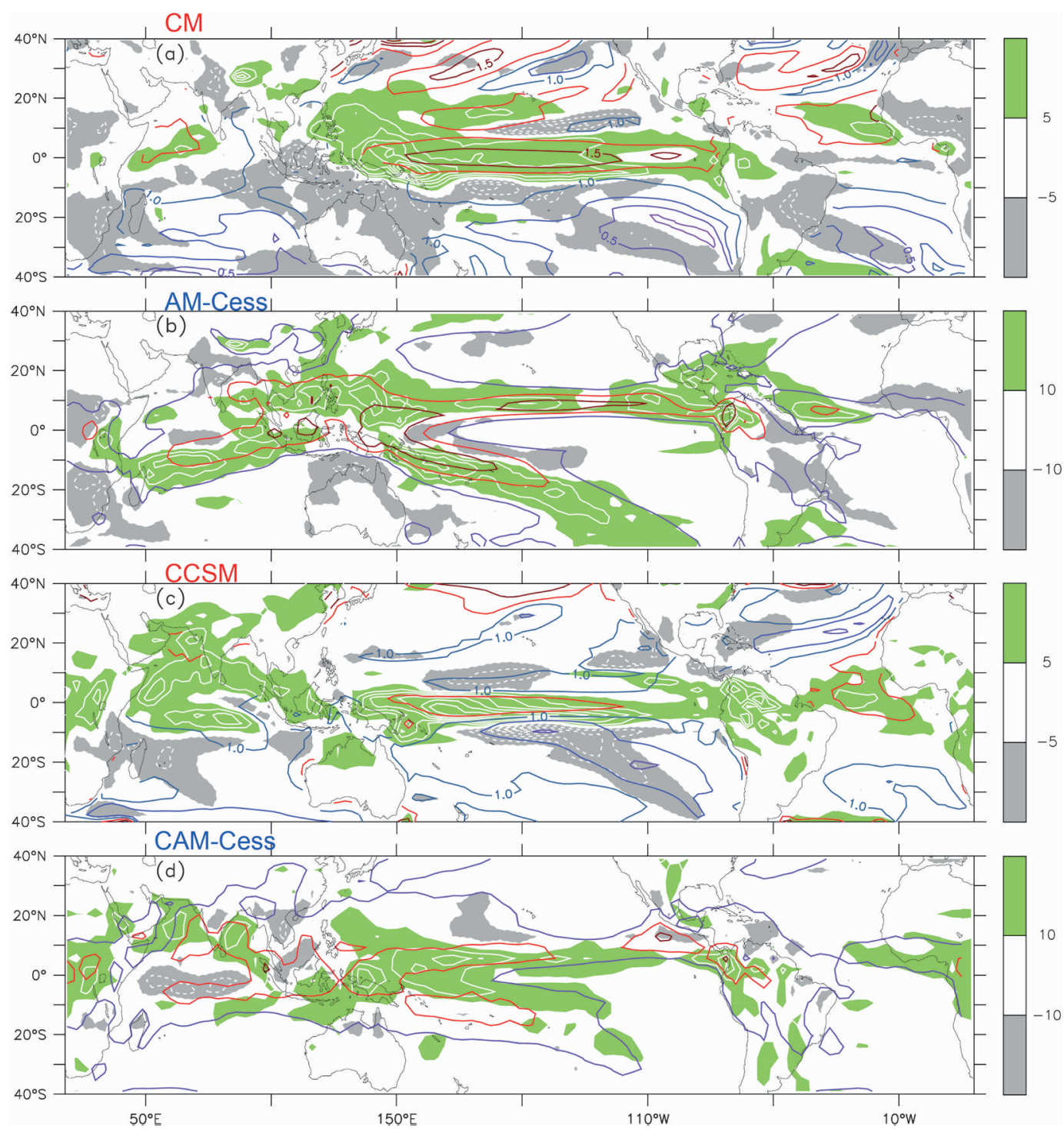

FIG. 10. Annual-mean precipitation change (green/gray shade and white contours, mm month ${ }^{-1}$ ): (a) CM2.1 A1B ensemble mean along with SST change (color contours, ${ }^{\circ} \mathrm{C}$ ) and (b) AM2.1 Cess $+2 \mathrm{~K}$ run along with mean precipitation (color contours at 100, 200, and $300 \mathrm{~mm} \mathrm{month}^{-1}$ ). Intervals for precipitation (white contours) are $10 \mathrm{~mm} \mathrm{month}^{-1}$ in (a) and $20 \mathrm{~mm}$ month $^{-1}$ in (b). (c),(d) As in (a),(b), but for CCSM3 A1B and CAM3 Cess +2 K runs.

Ocean ITCZ in CAM3. This wet-get-wetter pattern, while consistent with theoretical studies based on an implicit assumption of uniform SST warming (Chou and Neelin 2004; Held and Soden 2006; Chou et al. 2009), is very different from the coupled runs in spatial distribution. Over the tropical Pacific, for example, precipitation change is greatest on the equator in coupled runs (Figs. 1a,c), whereas it is large off the equator in atmospheric Cess runs (Figs. 1b,d). Large differences between the coupled and Cess runs reaffirm the conclusion that SST variations dominate the pattern formation in rainfall change under global warming. This happens because spatial variability in surface specific humidity change is much larger in coupled runs than in Cess runs, determined by spatial variations in SST warming (Fig. 11; appendix).

\section{Implications for tropical cyclone change}

Tropical cyclone change in global warming is of great socioeconomic concern and scientific interest. Recently, a body of work has emerged (e.g., Vecchi and Soden 2007a; Knutson et al. 2008; Swanson 2008; Vecchi et al. 2008; Zhao et al. 2009) suggesting that the SST change relative to the tropical mean, instead of its absolute local change, acts as a strong predictor of the local response of 


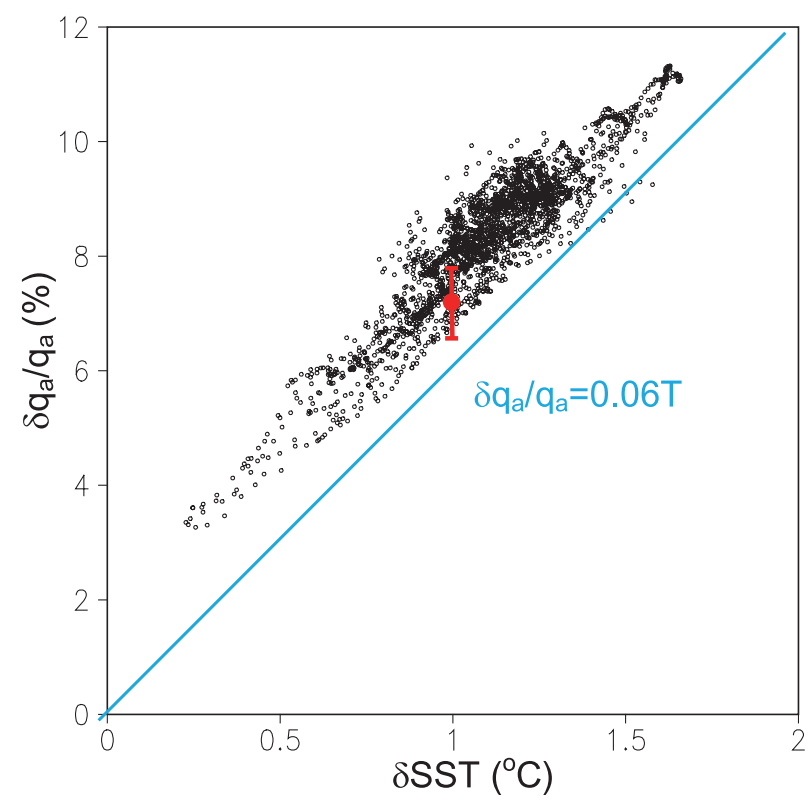

FIG. 11. Scatter diagram for spatial variations in annual-mean changes in SST and surface specific humidity in CM2.1 A1B within $20^{\circ} \mathrm{S}-20^{\circ} \mathrm{N}$. For comparison, the red dot and error bar indicate the mean and standard deviation in the AM Cess $+2 \mathrm{~K}$ run: $\left(\delta q_{a} / q_{a}\right) \times$ $100=7.2 T \pm 0.5$

TC activity to low-frequency global-scale climate changes. This argument is partly based on an atmospheric instability argument similar to the one presented in the appendix: upper-tropospheric warming is determined by tropical-mean SST, so change in moist instability is largely a function of SST deviations from the tropical mean. High-resolution downscaling simulations over the North Atlantic support this relative SST change hypothesis for TC frequency of occurrence (Knutson et al. 2008). In these simulations, the SST threshold for TC genesis increases with tropical warming (see also Yoshimura et al. 2006).

Equipped with a detailed knowledge of tropical SST patterns, we discuss their influence on TC based on the TC potential intensity (PI) index of Emanuel (1986). PI is proportional to the temperature between the surface inflow into and upper-tropospheric outflow of a TC. Emanuel (2007) shows that PI, instead of change in absolute SST, is a better index for thermodynamical effect on TCs. In CM, PI changes are highly correlated in space with relative SST changes ( $T^{*}$, Fig. 12), in support of Vecchi and Soden (2007a). During the Southern Hemisphere TC season of December-May, PI decreases nearly everywhere in $20^{\circ}-10^{\circ} \mathrm{S}$. During the Northern Hemisphere TC season of June-November, on the other hand, PI remains largely unchanged in the western and eastern Pacific genesis regions $\left(10^{\circ}-20^{\circ} \mathrm{N}\right)$ but increases in the North Atlantic main development region. Our
CM result for the North Atlantic is somewhat different from those of Vecchi and Soden (2007a) and Knutson et al. (2008) based on a multimodel ensemble, reflecting the sensitivity to SST patterns.

We highlight two tropical SST patterns that are robust and likely important for PI: a symmetric pattern with an equatorial peak and an antisymmetric pattern with larger warming north of the equator. The latter reduces PI and suppresses TC development in the Southern Hemisphere, but the amplitude of this antisymmetric pattern varies between CM and CCSM and among other models. The equatorial-enhanced warming, on the other hand, anchors the equatorial maximum in precipitation increase. Thus, the equatorial peak in SST warming is likely important for the magnitude of upper-tropospheric warming. The magnitude of this equatorial peak in SST is subject to uncertainties of model projection, but an increase in the SST peak can result in a global TC suppression as the off-equatorial SST warming cannot keep pace with the upper-tropospheric warming. Experiments have been carried out with a version of a high-resolution, global atmospheric general circulation model that shows skill in simulating the observed spatiotemporal variability of TC activity (Zhao et al. 2009). Preliminary results support the global TC suppression hypothesis; tropical storm activity in the model decreases in all basins in response to a $1.0^{\circ} \mathrm{C} \mathrm{SST}$ peak on the equator, with a global decrease of $27 \%$ in tropical storm counts (G. Vecchi 2009, personal communication). Detailed analysis of this experiment is underway and will be presented elsewhere, but these preliminary results illustrate the importance of this equatorial-enhanced SST pattern for TC activity. A similar reduction in $\mathrm{TC}$ frequency is reported in time-slice simulations with a high-resolution, global atmospheric GCM (Oouchi et al. 2006) in response to SST warming with an equatorial peak in the Pacific and Atlantic.

\section{Summary}

We have examined pattern formation in SST and precipitation responses to climate change based on ensemble simulations by GFDL and NCAR coupled ocean-atmosphere models under the A1B scenario. Although GHG concentrations are nearly uniform in space, substantial variations in SST warming emerge, both in the extratropics and the tropics. We have developed a physically based methodology that allows us to diagnose the causes of the SST patterns and their impact on rainfall. This study is a general survey intended to highlight the issues and stimulate further research.

Ocean circulation and surface flux adjustments are both important for SST pattern formation. Sometimes, oceanatmosphere interactions help shape spatial patterns. For 

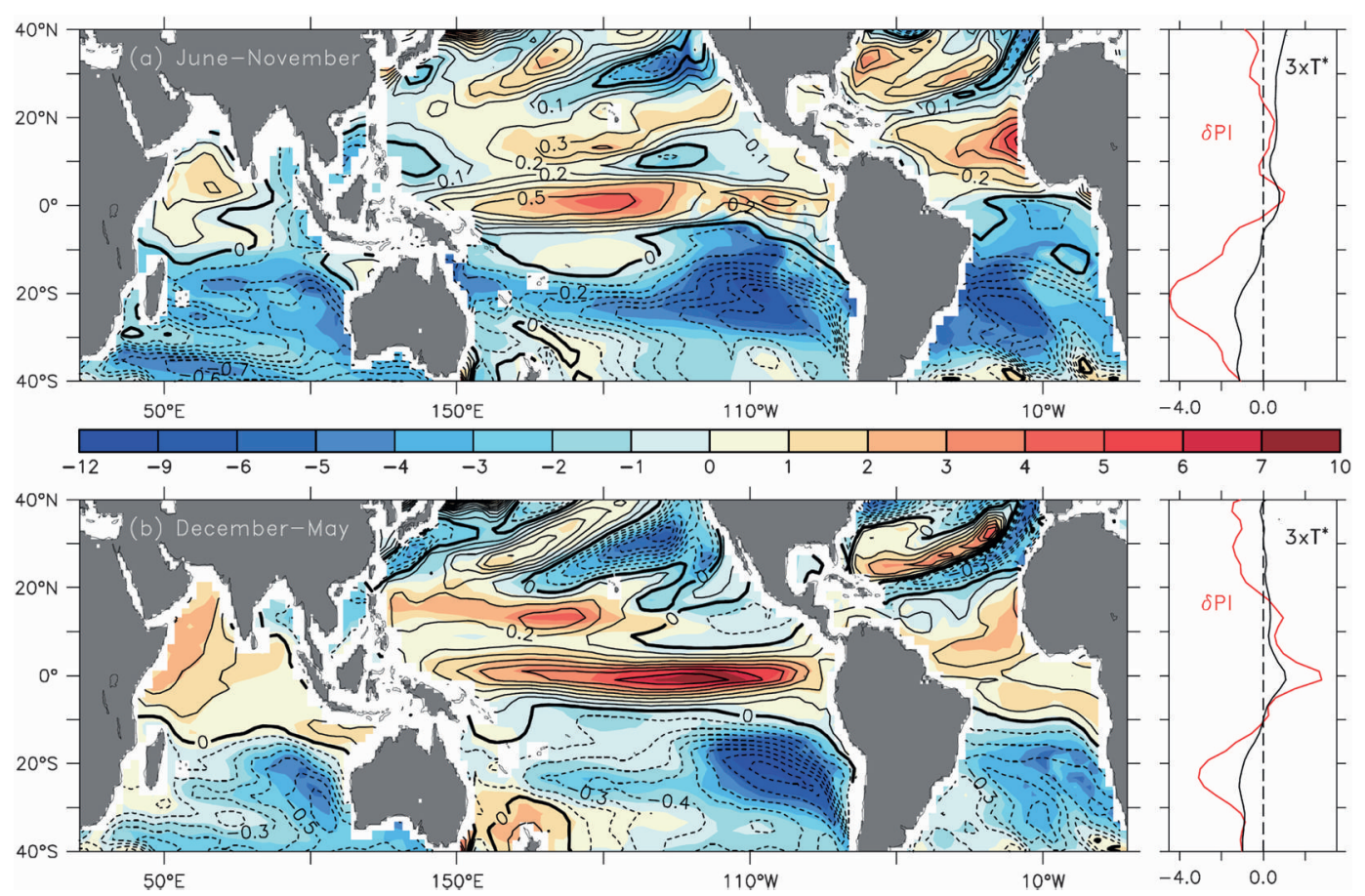

FIG. 12. Changes in tropical cycle potential intensity (PI) along with relative SST change $\left(T^{*},{ }^{\circ} \mathrm{C}\right)$ in $\mathrm{CM} 2.1 \mathrm{~A} 1 \mathrm{~B}$ for the (a) Northern and (b) Southern Hemisphere TC seasons. Zonal means are shown in the right-hand panels.

example, ocean dynamics is important for the IOD-like pattern in the equatorial Indian Ocean, aided by Bjerknes feedback with the atmosphere. It also creates the narrow banded structures in extratropical oceans where the mean SST gradients are large, on which anomalous currents imprint on SST readily by advection. Specifically, changes in mode water ventilation appear to be the main mechanism for narrow banded structures in surface current anomalies. This calls into question the errors in simulating the Gulf Stream and its effect on mode water formation.

Even without any change in ocean heat transport, adjustments among various surface flux components still create SST variations. Latent heat flux appears particularly important via WES feedback and the evaporative/ Newtonian damping for SST pattern formation. The former is commonly discussed in natural variability, while the latter mechanism is not. Because the coefficient of Newtonian damping on SST is inversely proportional to mean evaporation, SST warming peaks on the equator where mean evaporation is much weaker than in the subtropics. This equatorial enhanced warming pattern is most pronounced over the Pacific but also seen over the Atlantic in coupled atmosphere-OML simulations. In broad subtropical regions, wind speed changes appear to be the dominant mechanism for SST pattern formation. A strengthening of the southeast trades acts to reduce the
SST warming in the southern subtropics, especially over the Pacific. The northeast trades, by contrast, show a weakening tendency. This hemispheric asymmetry in trade wind change leads to a stronger warming in the northern than in the southern subtropics, suggestive of an interhemispheric WES feedback.

Most of the aforementioned patterns are common to CM, CCSM, and many other models. The equatorial Pacific maximum and subtropical southeast Pacific minimum are clearly visible in multimodel ensemble-mean SST (Fig. 10.9 of Meehl et al. 2007; Vecchi and Soden 2007a; Lu et al. 2008), so is the IOD-like pattern over the equatorial Indian Ocean (Vecchi and Soden 2007b; Du and Xie 2008). Despite the presence of many common large-scale features in the patterns of SST change in model projections of the twenty-first century, the details of the patterns can differ considerably from model to model, and the SST change patterns that will eventually emerge in the next few decades may still differ from the ensemble-mean model projection because of model and forcing errors as well as the superposition of natural variability on the radiatively forced signal. The mechanisms discussed in this paper, however, are likely to provide a useful guide to the interpretation and analysis of the patterns that do emerge.

The SST patterns highlighted above strongly affect precipitation, creating, among other features, an equatorial 
maximum in rainfall change over the Pacific. The correlation between precipitation change and spatial deviations of SST warming from the tropical mean is due to the fact that upper-tropospheric warming is nearly uniform in the tropics. As a result, the gross moist instability is dominated by spatial variations in SST change. We show that horizontal distributions of precipitation change in coupled simulations are different from the socalled wet-get-wetter pattern that dominates simulations with spatially uniform SST warming. In the latter Cess runs with a homogeneous increase in SST, spatial variations in gross moist instability change are due to those in mean precipitation, and precipitation increase largely avoids the equatorial Pacific because of weak rainfall in the mean. In coupled runs, by contrast, the enhanced SST warming in the equatorial Pacific anchors a band of large precipitation increase. We conclude that SST patterns are the dominant mechanism for precipitation change.

For the same reason, the relative SST change is important for tropical cyclone response to global warming (Vecchi and Soden 2007a; Knutson et al. 2008; Swanson 2008; Vecchi et al. 2008; Zhao et al. 2009). In particular, we suggest that the equatorial enhancement of warming (e.g., Liu et al. 2005) and the tendency for the Northern Hemisphere subtropics to warm more than the south in response to greenhouse forcing are likely to be important for the resulting TC changes. In an extreme case, a global TC suppression is possible if the equatorial peak in SST warming is sufficiently strong so that the offequatorial warming cannot keep up the pace and TC potential intensity decreases in $\mathrm{TC}$ genesis regions in the subtropics.

In this general survey, we have not been able to test in detail our proposed hypotheses for the various SST and precipitation response patterns. For example, connections are suggested in SST warming between the extratropics and subtropics via mode water ventilation in the Northern Hemisphere and WES feedback in the Southern Hemisphere. There is a possibility that the reduced warming in the Southern Ocean is a cause of interhemispheric asymmetry in subtropical SST warming. We intend to investigate these and other hypotheses in future studies.

Acknowledgments. We wish to thank Isaac Held, Kevin Trenberth, Jian Lu, Jerry Meehl, John Fasullo, Anand Gnanadesikan, Ken Takahashi, Tom Knutson, Gabriel Lau, Rong Zhang, Ingo Richter, Fumiaki Kobashi, and Hyodae Seo for helpful discussion; Adam Phillips for technical assistance; and Amy Clement and anonymous reviewers for helpful comments. Much of the work was conducted when SPX was on sabbatical leave at NCAR and GFDL. This work is supported by NOAA, NSF, NASA, and JAMSTEC.

\section{APPENDIX}

\section{Moist Instability Analysis}

We define a gross moist instability $\left(I_{M}\right)$ as the difference in moist static energy $h$ between the sea surface and upper troposphere (Neelin and Held 1987), say at $300 \mathrm{hPa}$,

$$
\left.I_{M} \equiv \delta h\right|_{300 \mathrm{hPa}} ^{\text {surface }}=\left.\left(c_{p} T_{a}+L q_{a}\right)\right|_{300 \mathrm{hPa}} ^{\text {surface }},
$$

where $T_{a}$ is air temperature anomaly. Figure A1a shows that, in the equatorial belt, upper-tropospheric temperature change $T_{T}$ varies by less than $0.3^{\circ} \mathrm{C}$, with its gradients flatted by fast equatorial wave adjustments (Sobel et al. 2001; Bretherton and Sobel 2002). As a result, moist stability change is dominated by SST variations (Fig. A1b). It increases in the equatorial belt, especially over the equatorial Pacific where SST warming is locally enhanced. It becomes negative in the southern subtropics as the increase in surface $h$ cannot keep up the pace of upper-tropospheric warming. In general, we can decompose SST warming or the change in $I_{M}$ into tropical mean and spatial deviations, denoted respectively by angle brackets and an asterisk; for example, $T=\langle T\rangle+$ $T^{*}$. The correlation with precipitation increases slightly if $I_{M}^{*}$ is used instead of $T^{*}$, to 0.60 from 0.56 in CM.

The dominance of SST in $I_{M}$ can be explained with the following analysis. From the empirical relationship (9),

$$
q_{a}^{*}=a\left\langle\bar{q}_{a}\right\rangle T^{*}+\bar{q}_{a}^{*}(a\langle T\rangle+b),
$$

where the overbar denotes the mean state. In coupled runs, $o\left(T^{*} /\langle T\rangle\right) \sim 1$, whereas spatial variations in basicstate surface humidity are much smaller than the tropical mean; that is, $o\left(\bar{q}_{a}^{*} /\left\langle\bar{q}_{a}\right\rangle\right) \ll 1$. Equation (A1) may be approximated with

$$
\frac{I_{M}^{*}}{c_{p}}=\left(1+\frac{a L\left\langle\bar{q}_{a}\right\rangle}{c_{p}}\right) T^{*}-T_{T}^{*},
$$

where the coefficient $a L \bar{q}_{a} / c_{p} \sim 2.6$ for $\left\langle\bar{q}_{a}\right\rangle=17 \mathrm{~g} \mathrm{~kg}^{-1}$ (we have neglected a small moisture effect on $h$ in the upper troposphere). Since spatial variations in $T_{T}$ are much smaller than those in SST, the gross moist instability change is dominated by SST variations, consistent with the apparent correlation in space between SST and precipitation. 

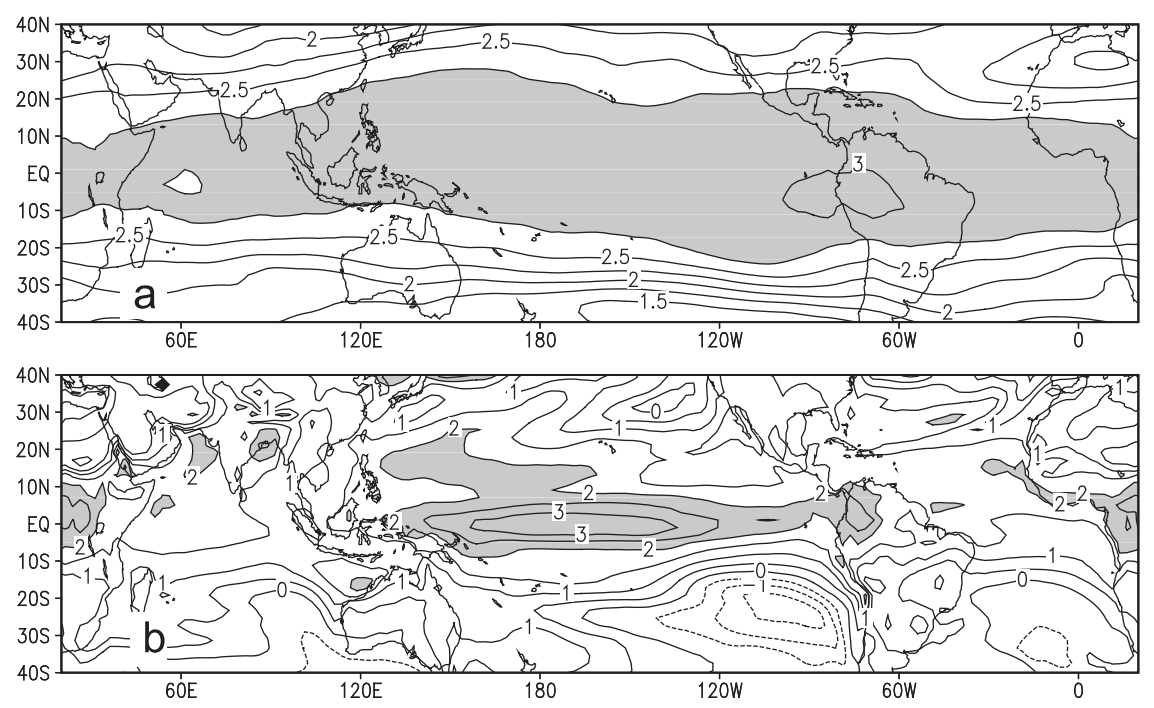

FIG. A1. Annual-mean change in CM2.1 A1B: (a) 300-hPa temperature (shading $>2.75 \mathrm{~K}$ ) and (b) gross convective instability $I_{M} / c_{p}$ (shading $>2 \mathrm{~K}$ ).

In Cess runs $\left(T^{*}=0\right)$, the percentage change in surface specific humidity is nearly uniform in space (Fig. 11). Equation (A1) becomes

$$
\frac{I_{M}^{*}}{c_{p}}=\frac{L}{c_{p}}(a\langle T\rangle+b) \bar{q}_{a}^{*}-T_{T}^{*} .
$$

As a result, precipitation change follows the pattern of mean specific humidity at the surface $\bar{q}_{a}^{*}$, which in turns follows largely mean precipitation.

\section{REFERENCES}

Alexander, M. A., I. Bladé, M. Newman, J. R. Lanzante, N. C. Lau, and J. D. Scott, 2002: The atmospheric bridge: The influence of ENSO teleconnections on air-sea interaction over the global oceans. J. Climate, 15, 2205-2231.

Allen, M. R., and W. J. Ingram, 2002: Constraints on future changes in climate and the hydrologic cycle. Nature, 419, 224-228.

Anderson, J. L., and Coauthors, 2004: The new GFDL global atmosphere and land model AM2-LM2: Evaluation with prescribed SST simulations. J. Climate, 17, 4641-4673.

Bjerknes, J., 1969: Atmospheric teleconnections from the equatorial Pacific. Mon. Wea. Rev., 97, 163-172.

Bony, S., and Coauthors, 2006: How well do we understand and evaluate climate change feedback processes? J. Climate, 19, 3445-3482.

Bretherton, C. S., and A. H. Sobel, 2002: A simple model of a convectively coupled Walker circulation using the weak temperature gradient approximation. J. Climate, 15, 2907-2920.

Cai, M., 2005: Dynamical amplification of polar warming. Geophys. Res. Lett., 32, L22710, doi:10.1029/2005GL024481.

Cane, M. A., A. C. Clement, A. Kaplan, Y. Kushnir, D. Pozdnyakov, R. Seager, S. E. Zebiak, and R. Murtugudde, 1997: Twentieth century sea surface temperature trends. Science, 275, 957-960.
Cess, R. D., and Coauthors, 1990: Intercomparison and interpretation of cloud-climate feedback processes in 19 atmospheric general circulation models. J. Geophys. Res., 95, 16 601-16 615.

Chang, P., and Coauthors, 2006: Climate fluctuations of tropical coupled system-The role of ocean dynamics. J. Climate, 19, 5122-5174.

Chen, G., J. Lu, and D. M. W. Frierson, 2008: Phase speed spectra and the latitude of surface westerlies: Interannual variability and global warming trend. J. Climate, 21, 5942-5959.

Chou, C., and J. D. Neelin, 2004: Mechanisms of global warming impacts on regional tropical precipitation. J. Climate, 17, 2688-2701.

,-- C.-A. Chen, and J.-Y. Tu, 2009: Evaluating the "richget-richer" mechanism in tropical precipitation change under global warming. J. Climate, 22, 1982-2005.

Clement, A. C., R. Seager, M. A. Cane, and S. E. Zebiak, 1996: An ocean dynamical thermostat. J. Climate, 9, 2190-2196.

Collins, W. D., and Coauthors, 2006: The Community Climate System Model version 3 (CCSM3). J. Climate, 19, 2122-2143.

Delworth, T. L., and Coauthors, 2006: GFDL's CM2 global coupled climate models. Part I: Formulation and simulation characteristics. J. Climate, 19, 643-674.

Deser, C., and A. S. Phillips, 2009: Atmospheric circulation trends, 1950-2000: The relative roles of sea surface temperature forcing and direct atmospheric radiative forcing. J. Climate, 22, 396-413.

_ A. Capotondi, R. Saravanan, and A. S. Phillips, 2006: Tropical Pacific and Atlantic climate variability in CCSM3. J. Climate, 19, 2451-2481.

de Szoeke, S. P., S.-P. Xie, T. Miyama, K. J. Richards, and R. J. O. Small, 2007: What maintains the SST front north of the equatorial cold tongue? J. Climate, 20, 2500-2514.

Dickinson, R. E., 1981: Convergence rate and stability of oceanatmosphere coupling schemes with a zero-dimensional climate model. J. Atmos. Sci., 38, 2112-2120.

DiNezio, P. N., A. C. Clement, G. A. Vecchi, B. J. Soden, B. P. Kirtman, and S.-K. Lee, 2009: Climate response of the equatorial Pacific to global warming. J. Climate, 22, 4873-4892. 
Du, Y., and S.-P. Xie, 2008: Role of atmospheric adjustments in the tropical Indian Ocean warming during the 20th century in climate models. Geophys. Res. Lett., 35, L08712, doi:10.1029/ 2008GL033631.

Emanuel, K. A., 1986: An air-sea interaction theory for tropical cyclones. Part I: Steady-state maintenance. J. Atmos. Sci., 43, 585-605.

_ 2007: Environmental factors affecting tropical cyclone power dissipation. J. Climate, 20, 5497-5509.

Gnanadesikan, A., and Coauthors, 2006: GFDL's CM2 global coupled climate models. Part II: The baseline ocean simulation. J. Climate, 19, 675-697.

Held, I. M., and B. J. Soden, 2006: Robust responses of the hydrological cycle to global warming. J. Climate, 19, 5686-5699.

Inatsu, M., and M. Kimoto, 2005: Two types of interannual variability of the mid-winter storm-tracks and their relationship to global warming. SOLA, 1, 61-64.

Kang, S. M., I. M. Held, D. M. W. Frierson, and M. Zhao, 2008: The response of the ITCZ to extratropical thermal forcing: Idealized slab-ocean experiments with a GCM. J. Climate, 21, 35213532 .

Knutson, T. R., and S. Manabe, 1995: Time-mean response over the tropical Pacific to increased $\mathrm{CO}_{2}$ in a coupled ocean-atmosphere model. J. Climate, 8, 2181-2199.

— J. J. Sirutis, S. T. Garner, G. A. Vecchi, and I. M. Held, 2008: Simulated reduction in Atlantic hurricane frequency under twenty-first-century warming conditions. Nat. Geosci., 1,359-364.

Leloup, J., and A. Clement, 2009: Why is there a minimum in projected warming in the tropical North Atlantic Ocean? Geophys. Res. Lett., 36, L14802, doi:10.1029/2009GL038609.

Liu, Z., 1998: On the role of ocean in the response of tropical climatology to global warming: The west-east SST contrast. J. Climate, 11, 864-875.

— S. Vavrus, F. He, N. Wen, and Y. Zhong, 2005: Rethinking tropical ocean response to global warming: The enhanced equatorial warming. J. Climate, 18, 4684-4700.

Lu, J., G. A. Vecchi, and T. Reichler, 2007: Expansion of the Hadley cell under global warming. Geophys. Res. Lett., 34, L06805, doi:10.1029/2006GL028443.

- G. Chen, and D. M. W. Frierson, 2008: Response of the zonal mean atmospheric circulation to El Niño versus global warming. J. Climate, 21, 5835-5851.

Manabe, S., K. Bryan, and M. J. Spelman, 1990: Transient response of a global ocean-atmosphere model to a doubling of atmospheric carbon dioxide. J. Phys. Oceanogr., 20, 722-749.

Meehl, G. A., W. D. Collins, B. A. Boville, J. T. Kiehl, T. M. L. Wigley, and J. M. Arblaster, 2000: Response of the NCAR Climate System Model to increased $\mathrm{CO}_{2}$ and the role of physical processes. J. Climate, 13, 1879-1898.

_ , and Coauthors, 2006: Climate change projections for the twenty-first century and climate change commitment in the CCSM3. J. Climate, 19, 2597-2616.

—_, and Coauthors, 2007: Global climate projections. Climate Change 2007: The Physical Science Basis, S. Solomon et al., Eds., Cambridge University Press, 747-845.

Neelin, J. D., and I. M. Held, 1987: Modeling tropical convergence based on the moist static energy budget. Mon. Wea. Rev., 115, $3-12$.

Oouchi, K., J. Yoshimura, H. Yoshimura, R. Mizuta, S. Kusunoki, and A. Noda, 2006: Tropical cyclone climatology in a globalwarming climate as simulated in a $20 \mathrm{~km}$-mesh global atmospheric model: Frequency and wind intensity analyses. J. Meteor. Soc. Japan, 84, 259-276.
Richter, I., and S.-P. Xie, 2008: The muted precipitation increase in global warming simulations: A surface evaporation perspective. J. Geophys. Res., 113, D24118, doi:10.1029/2008JD010561.

Saji, N. H., B. N. Goswami, P. N. Vinayachandran, and T. Yamagata, 1999: A dipole mode in the tropical Indian Ocean. Nature, 401, 360-363.

Schott, F. A., S.-P. Xie, and J. P. McCreary Jr., 2009: Indian Ocean circulation and climate variability. Rev. Geophys., 47, RG1002, doi:10.1029/2007RG000245.

Seager, R., and R. Murtugudde, 1997: Ocean dynamics, thermocline adjustment, and regulation of tropical SST. J. Climate, 10, 521-534.

Sobel, A. H., J. Nilsson, and L. M. Polvani, 2001: The weak temperature gradient approximation and balanced tropical moisture waves. J. Atmos. Sci., 58, 3650-3665.

Soden, B. J., and I. M. Held, 2006: An assessment of climate feedbacks in coupled ocean-atmosphere models. J. Climate, 19, 3354-3360.

Stouffer, R. J., 2004: Time scales of climate response. J. Climate, 17, 209-217.

Sutton, R. T., B. Dong, and J. M. Gregory, 2007: Land/sea warming ratio in response to climate change: IPCC AR4 model results and comparison with observations. Geophys. Res. Lett., 34, L02701, doi:10.1029/2006GL028164.

Swanson, K. L., 2008: Nonlocality of Atlantic tropical cyclone intensities. Geochem. Geophys. Geosyst., 9, Q04V01, doi:10.1029/ 2007GC001844.

Takahashi, K., 2009: Radiative constraints on the hydrological cycle in an idealized radiative-convective equilibrium model. J. Atmos. Sci., 66, 77-91.

Timmermann, A., F.-F. Jin, and M. Collins, 2004: Intensification of the annual cycle in the tropical Pacific due to greenhouse warming. Geophys. Res. Lett., 31, L12208, doi:10.1029/ 2004GL019442.

Trenberth, K. E., and J. T. Fasullo, 2009: Global warming due to increasing absorbed solar radiation. Geophys. Res. Lett., 36, L07706, doi:10.1029/2009GL037527.

Vecchi, G. A., and B. J. Soden, 2007a: Effect of remote sea surface temperature change on tropical cyclone potential intensity. Nature, 450, 1066-1070.

- and - 2007b: Global warming and the weakening of the tropical circulation. J. Climate, 20, 4316-4340.

, — , A. T. Wittenberg, I. M. Held, A. Leetmaa, and M. J. Harrison, 2006: Weakening of tropical Pacific atmospheric circulation due to anthropogenic forcing. Nature, 441, 73-76, doi:10.1038/nature04744.

- K. K. Swanson, and B. J. Soden, 2008: Whither hurricane activity? Science, 322, 687-689.

Vimont, D. J., J. M. Wallace, and D. S. Battisti, 2003: The seasonal footprinting mechanism in the Pacific: Implications for ENSO. J. Climate, 16, 2668-2675.

- M. Alexander, and A. Fontaine, 2009: Midlatitude excitation of tropical variability in the Pacific: The role of thermodynamic coupling and seasonality. J. Climate, 22, 518-534.

Williams, G. P., and K. Bryan, 2006: Ice age winds: An aquaplanet model. J. Climate, 19, 1706-1715.

Wittenberg, A. T., A. Rosati, N.-C. Lau, and J. J. Ploshay, 2006: GFDL's CM2 global coupled climate models. Part III: Tropical Pacific climate and ENSO. J. Climate, 19, 698-722.

Wu, L., Z. Liu, C. Li, and Y. Sun, 2007: Extratropical control of recent tropical decadal climate variability: A relay teleconnection. Climate Dyn., 28, 99-112. 
Xie, S.-P., and S. G. H. Philander, 1994: A coupled ocean-atmosphere model of relevance to the ITCZ in the eastern Pacific. Tellus, 46A, 340-350.

- T. Kunitani, A. Kubokawa, M. Nonaka, and S. Hosoda, 2000: Interdecadal thermocline variability in the North Pacific for 1958-97: A GCM simulation. J. Phys. Oceanogr., 30, 2798-2813. , H. Annamalai, F. A. Schott, and J. P. McCreary, 2002: Structure and mechanisms of South Indian Ocean climate variability. J. Climate, 15, 864-878.

Yin, J. H., 2005: A consistent poleward shift of the storm tracks in simulations of 21st century climate. Geophys. Res. Lett., 32, L18701, doi:10.1029/2005GL023684.
Yoshimura, J., M. Sugi, and A. Noda, 2006: Influence of greenhouse warming on tropical cyclone frequency. J. Meteor. Soc. Japan, 84, 405-428.

Zhao, M., I. M. Held, S.-J. Lin, and G. A. Vecchi, 2009: Simulations of global hurricane climatology, interannual variability, and response to global warming using a $50-\mathrm{km}$ resolution GCM. J. Climate, 22, 6653-6678.

Zheng, X.-T., S.-P. Xie, G. A. Vecchi, Q. Liu, and J. Hafner, 2010: Indian Ocean dipole response to global warming: Analysis of ocean-atmospheric feedbacks in a coupled model. J. Climate, in press. 